\title{
Una aproximación al culto imperial en Hispania: avances interpretativos
}

Carmen Alarcón Hernández

Universidad de Sevilla

carmen.alaher@gmail.com

Fecha recepción 01.05.2017 / Fecha aceptación 30.09.2017

\section{Resumen}

El presente trabajo ofrece una aproximación al culto imperial en la Península Ibérica. El análisis aborda los últimos estudios y avances interpretativos sobre su significado e introducción en Hispania $\mathrm{y}$, de acuerdo con las últimas investigaciones arqueológicas, examina uno de los procesos más importantes que experimenta la veneración a los emperadores en la Península: su organización provincial en la Bética, la Tarraconense y la Lusitania.

\section{Palabras clave}

culto imperial, sacerdotes provinciales, Hispania, sede provincial de culto imperial, domus imperatoria

\section{Abstract}

In this study, we present a critical approach to the imperial cult of the Iberian Peninsula. The analysis tackles the latest research and interpretative advances on the introduction of imperial worship in Hispania and, on the basis of the latest archaeological findings, we explore one of the most important processes of the imperial cult in the Iberian Peninsula: its provincial organization into Baetica, Tarraconensis and Lusitania.

\section{Keywords}

imperial cult, provincial priests, Hispania, provincial seat of imperial cult, domus imperatoria. 

«Murió [César] a los cincuenta y cinco años y fue incluido entre los dioses por voluntad expresa de los senadores, que contaron, además con el convencimiento del pueblo» ${ }^{1}$.

Suet. Iul. 88.

\section{Introducción}

Los extraordinarios honores que el Senado de Roma otorgó a César comenzaron tras su victoria en la batalla de Tapso en el año 46 a. C., cuando se decretó que se instalara en el Capitolio un carro suyo frente a la imagen de Júpiter y una estatua con una inscripción que lo denominaba «semidiós» (en palabras de Dion Casio) ${ }^{2}$. Posteriormente, después de la batalla de Munda, en el año 45 a. C., su efigie se colocó en el templo de Quirino; esta vez, con la inscripción «al dios invencible» ${ }^{3}$. Asimismo, durante los últimos meses de su vida se le concedió un flamen, un pulvinar para su imagen, un simulacrum y un fastigium ${ }^{4}$.

1. Periit sexto et quinquagensimo aetatis anno atque in deorum numerum relatus est, non ore modo decernentium, sed et persuasione uolgi.

2. Dio Cass. XLIII, 14, 6.

3. Dio Cass. XLIII, 45, 3.

4. I. Gradel, Emperor Worship and Roman Religion, Oxford, 2002, 54-55. Consúltese sobre los honores que recibió durante los últimos meses de su vida: Cic. Phil. 2, 43, 110; App. B. Civ. 2, 106; Suet. Iul. 76, 1; Iul. 84, 2; y Dio Cass. XLIV, 4-6. Posiblemente, el texto más claro al respecto sea el de Cicerón, escrito en el año 44 a. C., unos meses después de la muerte de César, y que se refiere a los honores que el dictador recibió antes de morir, entre los que se encuentra la concesión de un flamen que ocuparía Marco Antonio. Cic. Phil. 2, 43, 110: Et tu in Caesaris memoria diligens, tu illum amas mortuum? quem is honorem maiorem consecutus erat quam ut haberet pulvinar, simulacrum, fastigium, flaminem? est ergo flamen, ut Iovi, ut Marti, ut Quirino, sic divo Iulio M. Antonius. Quid igitur cessas? cur non inauguraris? sume diem, vide qui te inauguret: collegae summus; nemo negabit. O detestabilem hominem, sive quod tyranni sacerdos es sive quod mortui! La obra de referencia sobre Divus Iulius sigue siendo el trabajo de S. Weinstock, Divus Iulius, Oxford, 1971. Sobre su proceso de divinización y la configuración de su imagen de culto, véase: M. Koortbojian, The Divinization of Caesar and Augustus: Precedents, Consequences, Implications, Cambridge, 2013, 15-49. Consúltese también: 
Al margen del debate sobre si dichas honras supusieron la configuración de un culto oficial de Estado con anterioridad a su defunción ${ }^{5}$, ciertamente, la concesión de tales honores fue paralela a la consecución de sus victorias y a su progresiva concentración del poder. La amenaza que César suponía para los defensores de la República conllevó su asesinato; un acontecimiento que mostró a sus sucesores las consecuencias de aceptar de manera explícita, en la ciudad de Roma, honras equiparables a las concedidas a los dioses tradicionales. Como resultado, la proyección de la imagen del emperador como un primus inter pares determinó la forma que debía tomar la monarquía imperial; una creación política que fue definida en gran medida por Augusto, que evitó durante su vida un culto de Estado dirigido a su persona en Roma. No obstante, lo que ocurría a nivel municipal en las provincias y en el ámbito privado a veces difería del plan augusteo ${ }^{6}$. En este sentido, Scheid señala:

L'excès consistait, à Rome, dans le culte d'État, à revendiquer un culte direct de son vivant. Seuls les tyrans le firent. Un «bon» empereur se contentait, à ce niveau, d'un culte à son Génie, à son Numen, et à ses autres vertus, et bénéficiait par ailleurs dans les autres pratiques collectives, publiques ou domestiques, d'honneurs plus conséquents ${ }^{7}$.

La estrategia de Augusto es bien conocida. Se trataba de emprender una obra religiosa, enmascarada de tradicionalismo, pero que sin embargo sustentaba ideológicamente la figura del emperador y el nuevo sistema político, trayendo consigo las primeras manifestaciones de culto imperial en Roma. De este modo, además de tomar el control del ejército, los órganos de decisión y los principales sacerdocios de la ciudad ${ }^{8}$, el vencedor de Accio reaccionó contra el descuido de los deberes religiosos y de los espacios de culto de la ciudad, consecuencia de

D. Fishwick, The Imperial Cult in the Latin West. Studies in the Ruler Cult of the Western Provinces of the Roman Empire, I, 1, Leiden-Nueva York-Colonia, 1987, 56-72.

5. Sobre este debate, véase la opinión de Gradel, Koortbojian y Cole: Gradel, Emperor... op. cit., 5472; Koortbojian, The Divinization... op. cit., 15-49; y S. Cole, Cicero and the Rise of Deification at Rome, Cambridge, 2013, 170-184.

6. Gradel, Emperor... op. cit., 112: «On the state cult level, however, Augustus consistently avoided direct deification [...] On all other levels, however, namely those of provincial, municipal, and private cults, all of which were constitutionally irrelevant, there is no evidence that he was averse to the idea. In municipal cults we know of no prohibitions, and since such cults, depending entirely on local initiative, became very widespread indeed, active encouragement was superfluous; passivity was more than sufficient. The same appears to have been the case with private worship. On the provincial level, Augustus' regulation was limited to insisting that Roma be worshipped with him in the same temple».

7. J. Scheid, "Honorer le prince et vénérer les dieux: culte public, cultes de quartier et culte impérial dans la Rome augustéenne", en N. Belayche (ed.), Rome, les Césars et la Ville aux deux premiers siècles de notre ère, Rennes, 2001, 103.

8. Véase: Res Gestae Divi Augusti 7, 3. Consúltese también: M. Beard, J. North y S. Price, Religions of Rome, vol. 1, Cambridge, 2007, 186. 
las guerras civiles ${ }^{9}$. Así, «la restauration pieuse de ce que les adversaires avaient négligé, voir violé, au cours du conflit, était la meilleure façon de légitimer son pouvoir» ${ }^{10}$. Además, el nuevo princeps ajustó el día de la dedicación de determinados lugares sacros, reconstruidos y recuperados, con acontecimientos importantes en torno a la familia imperial ${ }^{11}$, vinculando la domus imperatoria con los rituales en honor a las divinidades tradicionales.

Por otro lado, con motivo de su regreso a Roma, tras sus victorias en la Galia e Hispania, el Senado decidió erigir un altar a la Pax Augusta, en el Campo de Marte junto a la Vía Flaminia, para celebrar el acontecimiento. El monumento fue dedicado el 30 de enero del año 9 a. C., coincidiendo con el cumpleaños de Livia ${ }^{12}$. Los aniversarios de dicha dedicación eran conmemorados con sacrificios por parte de los sacerdotes y magistrados de la ciudad ${ }^{13}$. Posteriormente, en el 4 d. C. se construyó el altar de la Providentia Augusta, también en la Vía Flaminia, y se dedicó el 26 de junio con motivo de la adopción de Tiberio por parte del emperador ${ }^{14}$. Dos años más tarde, el 17 de enero de $6 \mathrm{~d}$. C., el hijo de Livia consagró un altar al Numen Augusti en Roma, ajustando esta vez la dedicación del monumento con el aniversario del matrimonio de Augusto y Livia ${ }^{15}$. De este modo, con la reorganización territorial de la ciudad, por parte de Augusto, y la introducción de su genius en los Lares Compitales, llamados ahora Lares Augusti ${ }^{16}$, se completaba el desarrollo de una serie de rituales dirigidos a su genius, a su numen y a las virtudes imperiales.

9. Sobre sus reparaciones y construcciones más importantes en Roma, véase: Res Gestae Divi Augusti 1121. La restauración del bosque sagrado de Dea Dia (consúltese al respecto: J. Scheid, Romules et ses frères. Le collège des frères arvales, modèle du culte public dans la Rome des empereurs, Roma, 1990), el templo de Fors Fortuna (Ov. Fast. 6, 775 y s.), el Lupercal del Palatino o el templo de Júpiter Feretrio (Res Gestae Divi Augusti 19) materializan el esfuerzo de Augusto por recuperar la tradición, así como su intención de presentarse como un segundo Rómulo, refundador de la ciudad.

10. Scheid, "Honorer..., op. cit. 87.

11. Consúltese al respecto: P. Gros, Aurea templa. Recherches sur l'architecture religieuse à Rome à l’époque d’Auguste, Roma, 1976, 32 y s. Además, determinadas empresas constructivas, como fueron el templo de Divus Iulius, el de Júpiter Tonante del Capitolio, el de Apolo en el Palatino o el de Marte Vengador en su foro, estaban directamente ligadas a triunfos de Augusto. Véase: Scheid, "Honorer..., op. cit. 91-92. Asimismo, los cumpleaños de algunos miembros de la domus Augusta se celebraron con sacrificios dirigidos a los dioses tradicionales. Consúltese el estudio que realiza Scheid sobre las Actas de los Hermanos Arvales: J. Scheid, Commentarii fratrum arvalium qui supersunt. Les copies épigraphiques des protocoles annuels de la confrérie arvale (21 av.-304 apr. J.-C.), Roma, 1998, 14, no 5, f. 1. 1-3 (el cumpleaños de Livia se celebró el año 27 d. C. con un sacrificio a Júpiter), y 18, n 7, a, I, 1. 1-3 (el cumpleaños de Tiberio se celebró el año 33 d. C. con un sacrificio a Júpiter).

12. P. Zanker, Augustus und die Macht der Bilder, Múnich, 1997, 177-187.

13. Res Gestae Divi Augusti 12, 2.

14. Scheid, "Honorer...", op. cit. 97. También aparece mencionado en el senadoconsulto de Gneo Pisón Padre: W. Eck, A. Caballos y F. Fernández, Das senatus consultum de Cn. Pisone Patre, Múnich, 1996, 44, 1. 83-84.

15. Scheid, “Honorer..., op. cit. 98.

16. Dio Cass. LV, 8, 6 s.; Suet. Aug. 30, 1; y Plin. HN. 3, 5, 66. Consúltese por conveniencia: Beard, North y Price, Religions... op. cit., vol. 1, 207-208, y vol. 2, 184-186; y Gradel, Emperor... op. cit., 116-228. Véase la 
Aunque no se establecía una adoración directa del princeps, sí se le otorgaban una serie de privilegios divinos que se incluyen entre las primeras manifestaciones de culto imperial en Roma. Además, desde la consagración de Divus Iulius, Augusto se convirtió en Divi filius, por lo que su poder al frente del Imperio recibía la legitimación divina del nuevo Divus ${ }^{17}$. La formalización definitiva de la deificación de Julio César, de acuerdo con la consagración oficial que el Senado decretó a comienzos del año 42 a. C., proporcionó el modelo de las posteriores divinizaciones imperiales, en las que la iniciativa del renovado princeps fue determinante ${ }^{18}$.

Las provincias también desarrollaron un culto a los Divi, sin embargo, a diferencia de lo que ocurrió en Roma, a veces no esperaron a la consagración oficial del césar en la capital imperial para iniciar la concesión de una serie de honores divinos. Así ocurrió en muchas zonas del Oriente griego, pero también del Occidente latino, como en Hispania por ejemplo.

crítica de Scheid a la interpretación de Gradel en: J. Scheid, "Comprendre le culte dit impérial. Autour de deux libres récents”, L'Antiquité Classique, 73, 2004, 239-250.

17. Por su parte, César había explotado en su programa propagandístico la idea de que los Julios eran descendientes de la diosa Venus a través de Julio-Ascanio, hijo de Eneas. Sobre la relación del emperador con la diosa, véase: Weinstock, Divus... op. cit., 83-87. Con respecto a la importancia de la creación de una mitología en torno a la familia imperial en la legitimación de su poder divino, consúltese: F. Lozano, "Historias fabulosas: un aspecto de la construcción de la divinidad de los emperadores romanos", Habis, 39, 2008, 53-162.

18. S. Price, "From noble funerals to divine cult: the consecration of Roman emperors", en D. Cannadine y S. Price (eds.), Rituals of Royalty: Power and Ceremonial in Traditional Societies, Cambridge, 1987, 72. La ascensión a los cielos de Hércules y Rómulo configuró el ejemplo a seguir en las consagraciones de los emperadores en la capital imperial. Sobre los funerales imperiales, véanse: E. Bickerman, "Consecratio", en W. Den Boer (ed.), Le culte des souverains dans l'Empire Romain, Ginebra, 1973, 1-37; Price, "From noble...", op. cit. 56-105; J. Arce, Funus imperatorum. Los funerales de los emperadores romanos, Madrid, 1988; Gradel, Emperor... op. cit., 261-371; y F. Lozano, "El Más Allá de los emperadores: entre la divinización y el olvido", en F. Lozano, E. Ferrer y J. Mazuelos (coords.), Spal Monografías: Salvación, infierno, olvido. Escatología en el mundo antiguo, 2009, 153-173. Con respecto a la «teatralidad» del acto y la atmósfera que generan los funerales imperiales, consúltense: E. d'Ambra, "The imperial pyre as a work of ephemeral architecture", en B.C. Ewald y C.F. Noreña (eds.), The Emperor and Rome: Space, Representation, and Ritual, Cambridge, 2010, 289-308; y J. Arce, "Roman imperial funerals in effigie", en Ewald y Noreña (eds.), The Emperor... op. cit., 309-323. El reciente libro de Gnoli y Muccioli también profundiza en este aspecto: T. Gnoli y F. Muccioli, Divinizzazione, culto del soberano e apoteosi. Tra Antichità e Medievo, Bolonia, 2014. A pesar del objetivo y del significado político de dicha iniciativa, según la cita de Suetonio con la que se ha iniciado estas páginas, las deificaciones también contaron con el convencimiento de buena parte de la población sobre la condición sobrehumana del difunto. Con respecto a la importancia de la creencia en la divinidad del emperador, consúltense: Price, "From noble..., op. cit. 80-82; y Lozano, "Historias fabulosas..., op. cit. 153-162. 


\section{La compleja definición de «culto imperial»}

Para elaborar una aproximación a la veneración del princeps y su domus en la Península Ibérica es necesario establecer una definición coherente que concrete el tipo de testimonio al que se debe atender en su investigación en Hispania.

Actualmente se utiliza la denominación «culto imperial» para definir un conjunto de manifestaciones y prácticas muy heterogéneas a través de las cuales los habitantes del vasto Imperio romano expresaron, durante el Principado, el carácter sobrehumano de sus emperadores, así como de determinados miembros de su familia ${ }^{19}$. Como señala Scheid: «Le culte impérial nétait donc ni une usurpation d'honneurs divins, ni une divinisation pure et simple, mais un partage particulier des honneurs accordés sur terre à ceux qui paraissaient (ou voulaient) dépasser la condition et le pouvoir humains» ${ }^{20}$.

La designación «culto imperial» plantea una serie de problemas debido a que se trata de una denominación que no fue acuñada en la Antigüedad, por lo que este concepto no se usó en el contexto que se estudia para referir el conjunto de testimonios que actualmente se consideran característicos del mismo ${ }^{21}$. En mi opinión, la reflexión de Woolf al respecto es especialmente útil para comprender su complejidad: «[It is] a modern invention, a convenient taxonomic category that groups together a mass of discrete occasions on each of which the name and image of emperor, and sometimes also those of his relatives and ancestors, were given a place in essentially local rituals, temples, hymns, and prayers ${ }^{22}$.

En el caso de la Península Ibérica, la clásica obra de Étienne, Le culte impérial dans la Péninsule Ibérique d’Auguste à Dioclétien (1958), concretó los principales testimonios que se incluirían en las investigaciones posteriores sobre esta manifestación cultual en Hispania. Los posibles oficiantes de culto ${ }^{23}$, las abstracciones divinizadas de virtudes imperiales, los denominados dioses Augustos ${ }^{24}$ y los testimonios arqueológicos, escultóricos y numismáticos

19. Una de las últimas publicaciones sobre culto imperial destaca la importancia de la divinización de los diferentes miembros de la domus imperatoria en la construcción ideológica del poder imperial: G. McIntery, A Family of Gods. The Worship of the Imperial Family in the Latin West, Michigan, 2016.

20. Scheid, "Honorer..., op. cit. 89.

21. La información que proporcionan las fuentes clásicas reflejan el uso de determinados verbos como son: sacrificare (Suet. Iul. 85), precari (Ov. Ex Ponto, IV, 9, 105-112), venerare (Val. Max. Fact. 1, 6, 13), colere (Vell. Pat. II, 107), invocare (Apul. Met. III, 29). Asimismo, usan con frecuencia la denominación summi honores, divini honores y caelestes honores para hacer referencia a dichas honras.

22. G. Woolf, "Divinity and power in ancient Rome", en N. Brisch (ed.), Religion and Power: Divine Kingship in the Ancient World and beyond, Chicago, 242. Véase también la reflexión al respecto de Bickerman en: Bickerman, “Consecratio..., op. cit. 26.

23. R. Étienne, Le culte impérial dans la Péninsule Ibérique d’Auguste à Dioclétien, París, 1958, 121-283.

24. Sobre las virtudes imperiales y los dioses Augustos, consúltense: Étienne, Le culte... op. cit., 319-349; D. Fishwick, The Imperial Cult in the Latin West. Studies in the Ruler Cult of the Western Provinces of the Roman Empire, II, 1, Leiden-Nueva York-Colonia, 1991, 446-454 (para los dioses Augustos), 455-474 (para las virtudes imperiales); y J.R. Fears, "The cult of virtues and Roman Imperial Ideology", ANRW, 2, 17, 2, 1981, 827-948. El trabajo de Panciera es especialmente interesante: S. Panciera, "Umano, sovreumano o divino? Le divinità Auguste e l'imperatore a Roma", en L. de Blois et al. (eds.), The Representation and 
que aportan información sobre los espacios sagrados dedicados a la domus imperatoria ${ }^{25}$ se han convertido en el objeto de estudio de los que analizan el culto imperial en las provincias hispanas. Sin embargo, aún es mucho lo que se desconoce, pues no se tiene clara la función de sus sacerdotes, el significado que tenía incluir el epíteto Augustus/Augusta en el nombre de ciertas divinidades o, lo que es más importante, la concepción religiosa que las comunidades le otorgaron al culto o la creencia -de la que habla Suetonio en la cita con la que se ha iniciado estas páginas ${ }^{26}$ - en la divinidad del emperador.

\section{El culto imperial en Hispania: últimos estudios y avances interpretativos}

El trabajo de Étienne -Le culte impérial dans la Péninsule Ibérique d'Auguste à Dioclétien (1958) - supuso un gran avance en el conocimiento de la veneración de los emperadores en la Península Ibérica y sentó la base sobre la que se apoyarían las siguientes investigaciones. A pesar de los años transcurridos desde su publicación, su libro es lectura obligatoria para todo historiador interesado en el desarrollo del nuevo culto, con el que se inaugura el Principado, al menos en la parte occidental del Imperio.

Años más tarde, los estudios de Étienne fueron completados por la monumental obra de Fishwick, The Imperial Cult in the Latin West. Studies in the Ruler Cult of the Western Provinces of the Roman Empire (1987-2005). En relación a Hispania interesa especialmente el primer volumen, dedicado a los incipientes testimonios de esta manifestación cultual en el Occidente latino; pero también el último, publicado en cuatro tomos entre los años 2002 y 2005, en los que el autor desarrolla un detallado análisis sobre su organización supra-cívica -tanto de sus flamines provinciae como de las sedes de culto imperial provincial en Tarraco, Emerita y Corduba ${ }^{27}$.

Desde comienzos del s. XXI el progreso de las investigaciones se ha materializado en diferentes obras. Por un lado, Garriguet publicó en 2002 El culto imperial en la Córdoba romana: una aproximación arqueológica. En dicha publicación el autor elabora un estudio de los testimonios epigráficos, arqueológicos y escultóricos de culto imperial para aportar un panorama general sobre su evolución en la capital bética. Posteriormente, Nogales y González editaron la obra Culto imperial: política y poder, resultado del congreso internacional que se celebró en Mérida en mayo de 2006, donde se recogen los avances sobre su conocimiento en diferentes centros cívicos de la Península Ibérica. Dos años más tarde, Noguera editó el libro Fora Hispaniae. Paisaje urbano, arquitectura, programas decorativos y culto imperial en los

Perception of Roman Imperial Power: Proceedings of the Third Workshop of the International Network Impact of Empire (Roman Empire, c. 200 B.C -A.D. 476), Netherlands Institute in Rome, March 20-23, 2002, 2003, 215-239.

25. Véase la información que proporciona Étienne en la última sección de su libro donde trata la evolución del culto imperial en la Península Ibérica: Étienne, Le culte... op. cit., 355-517.

26. Suet. Iul. 88.

27. Fishwick, The Imperial... op. cit., I, 1 y 2; y Fishwick, The Imperial... op. cit., III, 2, 73-125, 139-154, y 215-247; III, 3, 5-104. 
foros de las ciudades hispanorromanas (2009), que incluye los últimos testimonios al respecto procedentes de los contextos forenses de las urbes hispanas. Por su parte, González Herrero publicó en 2015 La implantación del culto imperial de la provincia en Hispania, donde elabora un detallado análisis de los testimonios de los flamines provinciae Lusitaniae y de la organización del culto imperial en las provincias hispanas. En último lugar, se suma a la bibliografía el estudio que Fishwick desarrollaba antes de su muerte en 2015; una obra póstuma sobre su evolución en Tarraco y Emerita con el título de Precinct, Temple and Altar in Roman Spain. Studies on the Imperial Monuments at Mérida and Tarragona (2017).

\subsection{Una aproximación al significado del culto imperial en Hispania}

A pesar de la profusa bibliografía que ha generado el estudio de la veneración de la domus imperatoria en Hispania, a diferencia de lo que ocurre en otras zonas del Imperio, la teorización sobre su significado no es muy abundante en los trabajos que tratan este aspecto de la religión romana en la Península Ibérica.

En gran medida, Fishwick ha sido quien ha determinado las líneas interpretativas en el Occidente latino, en general, y en las provincias hispanas, en particular. Se observa, incluso, una evolución de sus ideas en sus publicaciones, pues en un primer momento afirma que «the real significance of the worship of the Roman emperor, particularly in its provincial application, lies not in the realm of religion at all but in a far different field: that of practical government, wherein lay the historic destiny of the Roman people» ${ }^{28}$. Posteriormente, en sus trabajos más recientes, el autor sí incluye los caelestes honores entre las manifestaciones religiosas del Principado, estableciendo, sin embargo, una clara diferencia entre los sacrificios y dedicaciones por la salud del emperador (pro salute imperatoris) y los que se les dirigían directamente como al resto de deidades. Aunque, según Fishwick, todos forman parte de lo que denomina «the imperial religion», sólo los últimos se pueden incluir entre los rituales de culto imperial, ya que trataban a sus destinatarios como verdaderas divinidades:

Dedications to a god on behalf of the emperor's well-being essentially associate a truly religious devotion with homage to the ruler, the designated and predestined vicar of the gods. It follows that the pro salute formula, while certainly part of imperial religion, is a manifestation not of ruler cult but of loyalty to the emperor ${ }^{29}$.

28. D. Fishwick, "The development of provincial ruler worship in the western Roman Empire", ANRW, $2,16,2,1978,1252-1253$. Otra cita representativa sobre sus primeras aproximaciones teóricas al culto imperial es la siguiente: «The cult of the ruler could on occasion have elements in common with the modern conception of true religiosity, with its Christian perspective. If worship is to be limited to the mediation of graces in a supernatural way, then the term is obviously inappropriate within the context of Gottmenschentum». Fishwick, The imperial... op. cit., I, 1, 44.

29. Fishwick, The imperial... op. cit., III, 3, 360. La solución que propone Friesen a este asunto es diferente. Véase al respecto: S.J. Friesen, Twice Neokoros. Ephesus, Asia and the Cult of the Flavian Imperial Family, Leiden, 1993, 151-152. 
Una mirada sobre el desarrollo de la investigación en otras zonas del orbe romano revela que las recientes corrientes interpretativas -herederas del nuevo planteamiento teórico que expuso Price en su trabajo sobre Asia Menor- no están dispuestas a aceptar el anacronismo que supone disociar los conceptos de religión y política en el contexto de la Antigüedad, e incluir el culto imperial únicamente en una de estas dos categorías ${ }^{30}$.

Asimismo, teniendo en cuenta la diversidad de rituales que existieron en torno a la figura del emperador, los últimos estudios también han puesto de manifiesto la complejidad que supone definir su estatus. Ciertamente, como señala Lozano, la inexistencia de una única teoría sobre la relación del césar con los dioses evitó la proliferación de una imagen uniforme y homogénea del mismo. Como resultado, la variedad de formas que tomó la divinidad imperial durante el Principado fue consecuencia de la convivencia de numerosos modos de entender al princeps que complicaron la comprensión de su doble condición, divina y humana ${ }^{31}$.

Los testimonios hispanos parecen apoyar esta hipótesis. Por un lado, existieron consagraciones dirigidas directamente al emperador. En este sentido, Mangas ha estudiado, en los últimos años, el significado que para la organización del culto imperial en el noroeste peninsular tuvieron una serie de Arae Augustae, documentadas a través de fuentes epigráficas y literarias, y que fueron dedicadas al primer princeps $^{32}$. También cabe destacar el altar votivo de cuerpo cilíndrico elaborado en caliza local que fue hallado en Trigueros (Huelva), en un ambiente descontextualizado debido a su reutilización como brocal de pozo, y que ha sido estudiado por Beltrán y Stylow. Tras el detallado análisis, tanto de su inscripción como de las representaciones que incorpora, los autores concluyen que el altar informa de la conce-

30. S. Price, Rituals... op. cit., 1984. Consúltense los antecedentes teóricos de la obra de Price en: K. Hopkins, "Divine emperors or the symbolic unity of the Roman Empire", Conquerors and Slaves, Cambridge, 1978, 197-242. En palabras de Gnoli y Muccioli, la obra de Price es «una monografia che a tutt'oggi costituisce uno dei capisaldi nel nuovo paradigma». Gnoli y Muccioli, Divinizzazione... op. cit., 21. En cuanto a la presencia de las teorías de Price en las últimas publicaciones sobre culto imperial, véase: S.J. Friesen, Imperial Cults and the Apocalypse of John: Reading Revelation in the Ruins, 2001, Oxford; Gradel, Emperor... op. cit.; B. Burrell, Neokoroi: Greek Cities and Roman Emperors, Leiden, 2004; M. Kantiréa, Les dieux et les dieux augustes. Le culte impérial en Grèce sous les Julio-claudiens et les Flaviens. Études épigraphiques et archéologiques, Atenas, 2007; F. Lozano, Un dios entre los hombres. La adoración a los emperadores romanos en Grecia, Barcelona, 2010; F. Camia, Theoi Sebastoi: Il culto degli imperatori romani in Grecia (provincia Achaia) nel secondo secolo D.C., Atenas, 2011; y G. Frija, Les prêtres des empereurs: le culte impérial civique dans la province romaine d'Asie, Rennes, 2012.

31. Lozano, Un dios... op. cit., 31-33.

32. J. Mangas, "El culto imperial en el noroeste de Hispania”, en T. Nogales y J. González (eds.), Culto imperial: política y poder. Actas del Congreso Internacional: culto imperial: política y poder, Mérida, Museo Nacional de Arte Romano, 18-20 de mayo, 2006, Roma, 2007, 705-720; In Astyrum litore Noega est oppidum, et tres arae quas Sestianas vocant in paeninsula seden et sunt Augusti nomine sacrae inlustrantque terras ante ignobiles (Pomp. Mel. Chorographia, 3, 13); Imp(eratori) Caesari Augusto Divi f(ilio) / co(n)s(uli) XIII imp(eratori) XX pont(ifici) max(imo) / patr(i) patriae trib(unicia) pot(estate) XXXII / [[ Gnaeus Calpurnius Piso leg(atus) pro pr(aetore) pr(ovinciae)]] sacrum (CIL II, 2703); Imp(eratori) Caesari Divif(ilio) Aug(usto) / pont(ifici) max(imo) trib(unicia) pot(estate) XXI / sacrum / Bracaraugustani / Paulli Fabi Maxsimi leg(ati) pro pr(aetoris) / natali dedicata est (EE, 8, 280). Véase también: CIL II, 5182 y CIL II2/7, 69. 
sión de un donum, por iniciativa de unos particulares, posiblemente al emperador Augusto "considerándolo en la práctica dirigente del cosmos celeste y benefactor de la humanidad» ${ }^{33}$.

No obstante, también se constatan dedicaciones y rituales por la salud del princeps y los miembros de su domus ${ }^{34}$. Recientemente, ha sido publicada la inscripción que recoge una lápida moldurada con un texto votivo de carácter ritual, procedente de la colonia Augusta Firma. Según la interpretación de los autores, se trata de una votorum nuncupatio realizada pro salute imperatoris en beneficio, posiblemente, del emperador Cómodo el día de su natalicio en algún momento entre los años 190-192 $2^{35}$. De acuerdo con la reconstrucción de la lectura de la inscripción que realizan los editores, así como la información que las Actas de los Hermanos Arvales proporcionan sobre este tipo de fórmulas rituales, el texto comenzaría con un llamamiento a Júpiter Óptimo Máximo al que se le hace la petición, seguido del nombre del beneficiario, mencionado en calidad de hijo de la divinidad (filius tuus $)^{36}$.

Las últimas corrientes interpretativas que ahondan en el significado del culto imperial otorgan un papel fundamental al concepto de «poder». Las publicaciones de Gradel, Woolf, Lozano y Gordon son un buen ejemplo ${ }^{37}$. En estos estudios se considera que la veneración

33. J. Beltrán y A.U. Stylow, "Un aspecto del culto imperial en el suroeste bético: el 'punteal' de Trigueros (Huelva), un altar dedicado a Augusto”, en Nogales y González (eds.), Culto... op. cit., 247. El texto del epígrafe documenta la concesión de un donum (el altar) posiblemente a Augusto por iniciativa de Gayo Sempronio Próculo Serviliano y Gayo Sempronio Serviliano, que fue dedicado por Sempronia Anulia: Donum Aug(usto) C(aius) Sempronius Gal(eria) Proculus Servilianus et C(aius) Sempronius C(ai) f(ilius) Gal(eria) Servilianus d(ederunt o dant) / Sempronia Anull[ina] ded(icavit o dedicat). Sobre la lectura de la inscripción, véase: Beltrán y Stylow, “Un aspecto...”, op. cit. 244. Además del texto que informa de la dedicación, cabe destacar la representación -en la cara exterior y cilíndrica del ara- de cuatro erotes desnudos que se intercalan con el mismo número de animales, ilustrando diferentes signos zodiacales: Leo (a través de la imagen de un león), Aries (con un carnero), Capricornio (mediante la representación de una cabra) y Sagitario (a través de un centauro). Los erotes sostienen una gruesa guirnalda de hojas de laurel decorada por una cinta que se ve en los espacios que dejan libres dichas figurillas desnudas. Consúltese sobre la interpretación de la representación: Beltrán y Stylow, “Un aspecto..., op. cit. 243. Mediante un análisis de la decoración del ara, los autores proponen vincular la representación de Capricornio con Augusto, mientras que los signos de Aries, Leo y Sagitario, que conforman un trígono zodiacal, sintetizarían todo el Zodiaco «y, por ende, el mundo celeste en el que domina el Capricornio, es decir, Augusto» (p. 246).

34. Véanse, por ejemplo: CIL II2/7, 233, y CILA 3, 36.

35. Véanse todos los detalles sobre la inscripción y la reconstrucción e interpretación del texto en: J. C. Saquete, S. Ordóñez y S. García-Dils, "Una votorum nuncupatio en Colonia Augusta Firma (Écija, Sevilla)", Zetischrift für Papyrologie und Epigraphik, 176, 2011, 281-290. Sobre el material de la inscripción, consúltese: S. Ordóñez et al., "A votorum numcupatio from colonia Augusta Firma. An analitical approach", en P. Pensabene y E. Gasperini (eds.), Interdisciplinary Studies on Ancient Stone. ASMOSIA X. Proceedings of the Tenth International Conference of ASMOSIA (Association for the Study of Marble and Other Stones in Antiquity), Rome, 21-26, May 2012, Roma, 2015, 263-268.

36. Saquete, Ordóñez y García-Dils, “Una votorum...”, op. cit. 284.

37. Gradel, Emperor... op. cit.; Woolf, “Divinity...”, op. cit. 235-251; F. Lozano, “The creation of imperial gods: not only imposition versus spontaneity”, en P.P. Iossif, A.S. Chankowski y C.C. Lorber (eds.), More than Men, Less than Gods. Studies on Royal Cult and Imperial Worship. Proceedings of the International 
del emperador fue consecuencia de su monopolización de un poder absoluto, así como de su capacidad para mantener el sistema imperante y favorecer acciones benefactoras y evergéticas sobre la población de su Imperio ${ }^{38}$. Además, se observa cómo a pesar de su humanidad y de sus posibilidades políticas reales, las imágenes que se proyectan del princeps sugieren que gozaron de un poder ilimitado, comparable al que poseían los dioses tradicionales ${ }^{39}$. Como resultado, independientemente de si las acciones de culto se dirigieron directamente al princeps, a su genius, a su numen, a las virtudes imperiales, si se invocaba a otra deidad por su salud (pro salute imperatoris) o si el cultus tenía por objeto los Divi y Divae, la brecha que marcaba la diferencia de poder que existía entre la domus Augusta y el resto de la comunidad se materializaba en estos actos litúrgicos ${ }^{40}$. Se puede considerar, por tanto, que la veneración de la familia imperial fue consecuencia de un proceso de sacralización del poder.

\subsection{Avances interpretativos sobre el origen del culto imperial en Hispania}

Las primeras manifestaciones de culto imperial en Hispania son de época augustea. Baste como ejemplo la breve anécdota que recoge Quintiliano sobre el altar que los tarraconenses dedicaron a Augusto en Tarraco. Según el retórico hispanorromano, después de su estancia en la colonia (26-25 a. C. $)^{41}$, cuando ya estaba de vuelta en Roma, se le informó de que había crecido una palmera sobre el altar que le habían consagrado en la ciudad ${ }^{42}$. El acontecimiento fue recordado en una serie de dupondios y semis de bronce acuñados en Tarraco en época de Tiberio $^{43}$.

La interpretación que ha dominado la explicación sobre la rápida acogida de la veneración del emperador en la Península Ibérica es la que planteó Étienne. En su opinión,

Colloquium organized by the Belgian School at Athens (November, 1-2, 2007), Lovaina-París-Walpole (Massachusetts), 2011, 475-519; y R.L. Gordon, "The Roman imperial cult and the question of the power", en J. North y S. Price (eds.), The Religious History of the Roman Empire: Pagans, Jews and Christians, Oxford, 2011, 37-70.

38. Véase: Lozano, “The creation..., op. cit. 504-505: «He is venerated concurrently as incarnation and symbol of the uneven distribution of power in the imperial Mediterranean world, a process that have been defined earlier as religious naturalization of power».

39. Gordon, "The Roman...", op. cit. 53-54. Consúltense, por conveniencia, las recientes interpretaciones sobre el culto a los gobernantes de Versnel e Iossif y Lorber: H.S. Versnel, Coping with the Gods: Wayward Readings in Greek Theology, Leiden, 2011; y P.P. Iossif y C.C. Lorber, "More than men, less than gods: concluding thoughts and new perspectives", en Iossif, Chankowski y Lorber (eds.), More... op. cit., 691-710.

40. Gradel, Emperor... op. cit.

41. Tal y como recoge Dion Casio (LIII, 25), Augusto quiso asumir personalmente la campaña militar contra los cántabros y astures en Hispania, pero las dificultades del enfrentamiento afectaron a su salud y tuvo que retirarse a Tarraco, donde permanecería dos años. Según Suetonio (Aug. 26, 3) en esta ciudad tomó posesión de su octavo y noveno consulado, correspondientes a los años 26 y 25 a. C.

42. Quint. Inst. Orat. VI, 3, 77: Et Augustus nuntiantibus Tarraconensibus palmam in ara eius enatam, apparet, inquit, quam saepe accendatis.

43. $R P C$ I, 218, 221, 225, 231. 
el prematuro advenimiento que el culto a Augusto tuvo en Hispania fue consecuencia de la previa existencia de una práctica que consideró característica de las comunidades prerromanas: la devotio ibérica ${ }^{44}$. Su explicación, aceptada por buena parte de los estudiosos ${ }^{45}$, es puesta actualmente en duda de acuerdo con las revisiones que se han elaborado sobre dicha institución ibérica ${ }^{46}$.

Mangas expuso su opinión al respecto en su contribución al congreso internacional de Mérida de 2006 en su trabajo "El culto imperial en el noroeste de Hispania" (2007):

Parece que es posible entender el comportamiento de los devoti como el de las bandas armadas de necesitados, dirigidas por un jefe, puestas al servicio de causas ajenas y cohesionadas por un juramento militar. Esos rasgos, bastantes universales, no preparan una mentalidad específica de los hispanos para disponerlos de un modo particular a la aceptación de un culto al jefe extranjero ${ }^{47}$.

Posteriormente, Lozano y Alvar volvieron sobre esta cuestión en su artículo "El culto imperial y su proyección en Hispania" (2009), en el que declararon que «a pesar de lo sugerente que pueda resultar esta reconstrucción, no existió tal relación entre surgimiento de culto imperial y devotio ibérica [...] la devotio no forma parte del entramado religioso, prerrogativa que, en cambio, sí tenía el culto imperial [...] la devotio no implicó la celebración de culto religioso al jefe» ${ }^{48}$.

44. Étienne, Le culte... op. cit., 362: «Il faut donc dépasser l'idée que, seule, l'Italie a pu trouver dans son passé des exemples d'un culte dédié à un homme: ici, nous avons l'exemple d’une province qui a connu par la devotio, le culte d'un homme». Algunos trabajos significativos sobre la devotio ibérica son los siguientes: J.M. Ramos y Loscertales, "La devotio ibérica", Anuario de Historia del Derecho Español, 1, Madrid, 1924, 7-26; F. Rodríguez, "La fides ibérica", Emerita, 14, Madrid, 1946, 128-209; A. Prieto, "La devotio ibérica como forma de dependencia en la Hispania Prerromana”, Memorias de Historia Antigua, 2, Oviedo, 1978, 131-135; Ma Dopico, "La devotio ibérica: una revisión crítica", en J. Mangas y J. Alvar (eds.), Homenaje a José María Blázquez, vol. 2, Madrid, 1994, 181-193; J. Alvar, "Discusión sobre las instituciones ibéricas", en M. Garrido-Hory y A. González (eds.), Histoire, espaces et marges de l'Antiquité, vol. 3. Hommages à Monique Clavel- Lévêque, Besanzón, 2004, 11-31; y F. Greenland, "Devotio iberica and the manipulation of the ancient history to suit Spain's mythic Nationalist past”, Greece \& Rome, 53, 2, Oxford, 2006, 235-253.

45. L.A. Curchin, Roman Spain. Conquest and Assimilation, Londres-Nueva York, 1991, 162; L.A. Curchin, "Cult and Celt: indigenous participation in emperor worship in Central Spain", en A. Small (ed.), Subject and Ruler: The Cult of the Ruling Power in Classical Antiquity, Ann Arbor, 1996, 152; D. Fishwick, "Four temples at Tarraco", en Small (ed.), Subject... op. cit., 184; A. Canto, "Notas sobre los pontificados coloniales y el origen del culto imperial en la Bética”, La religión romana en Hispania, Madrid, 1981, 151; y M. MartínBueno, "El culto imperial en el valle del Ebro", en Nogales y Gonzalez (eds.), Culto... op. cit., 725.

46. Consúltense por conveniencia: Dopico, “La devotio..., op. cit. 181-193; Alvar, “Discusión...”, op. cit. 11-31; y Greenland, “Devotio ibérica...”, op. cit. 235-253.

47. Mangas, “El culto..., loc. cit. 709.

48. F. Lozano y J. Alvar, "El culto imperial y su proyección en Hispania”, en J. Andreu, J. Cabrero e I. Rodà (coord.), Hispania. Las provincias hispanas en el mundo romano. El rol y la imagen de Hispania en las provincias Occidentales del Imperio, Tarragona, 2009, 430. 
Un vistazo general sobre los testimonios de culto imperial en las provincias hispanas muestra que su integración y desarrollo fue más rápido, y su implantación más profunda, en las regiones con amplia concentración de centros cívicos que en las zonas con focos poblacionales más dispersos; asimismo, progresó con más facilidad en los territorios volcados al Mediterráneo que en espacios ajenos a las influencias que viajaban a través de esta vía de comunicación. En efecto, los rituales de culto imperial se incluyeron en la religión cívica, los foros de las ciudades acogieron espacios dedicados a la veneración del emperador y su domus, y los teatros y los edificios de espectáculo fueron incluidos en las fiestas en honor a la familia imperial. Así, la nueva práctica religiosa con la que se inaugura el Principado fue un rasgo de «romanidad» y se inició, precisamente, en primer lugar en las zonas más próximas culturalmente a Roma ${ }^{49}$. No obstante, esta afirmación debe ser matizada, pues como Marco Simón ha señalado recientemente, un buen número de testimonies de época augustea indican que los comandantes militares propiciaron e iniciaron el proceso en determinadas áreas de Hispania, como el noroeste peninsular ${ }^{50}$.

Por otro lado, la élite cívica constituyó uno de los principales motores del desarrollo de la veneración a la domus imperatoria en las urbes hispanas. Con las deducciones coloniales y las constituciones municipales se configuró un nuevo grupo de notables que acaparó las magistraturas de la ciudad y ocupó los principales sacerdocios de culto imperial. Los primeros pontífices de Augusto en Italica, para los que González ha propuesto una cronología augustea, son buen ejemplo de ello ${ }^{51}$. L. Blattius L. f. Traianus Pollio y C. Traius C. f. Pollio fueron, además de duoviri por segunda vez, pontífices primi creati Augusto y llevaron a cabo una acción evergética que consistió en la financiación de la orchestra, el proscaenium, los itinera, las arae y los signa del teatro del municipio, espacio claramente vinculado al culto imperial ${ }^{52}$.

49. Lozano y Alvar, "El culto imperial...", op. cit. 430-431. Además, como ya señaló Salinas hace años, los rituales de culto imperial florecieron, en primer lugar, en las áreas más próximas culturalmente a Roma y no en aquéllas en las que las fuentes constatan la devotio, como es el caso de la Celtiberia. Véase: M. Salinas, Conquista y romanización de Celtiberia, Salamanca, 1986, 196-197. En la publicación que Woolf dedicó a este asunto ("Divinity and power in Ancient Rome", 2008), el autor esbozó un panorama de un mundo mediterráneo interconectado, como el que presentan Horden y Purcell (P. Horden y N. Purcell, The Corrupting Sea: A study of Mediterranean History, Oxford, 2005), a través del cual las ideas se extienden rápidamente en las urbes volcadas a esta vía de influencia, ya que durante el Principado los niveles de comercio y migración fueron muy altos. Woolf, "Divinity..., op. cit. 247-248: «That world shared a long heritage of interaction, often at the cultic level, and was more recently united by the common traumas of conquest and civil world. When autocracy emerged (or re-emerged) from the convulsions, all parties participated in formulating religious responses [...] as a result, there were few if any communities who did not find some place for the emperors in their ritual lives».

50. F. Marco Simón, “Los inicios del culto imperial en la Hispania augustea”, Gerión, 35, 2017, 773-789.

51. J. González, “El origen del culto imperial en la Bética según la documentación epigráfica”, en Nogales y González (eds.), Culto... op. cit., 183. Otros sacerdocios de culto imperial para los que se propone una cronología temprana son los siguientes: Pontifex Aug(usti) (Carmo, CIL II, 1380); flamen Caesaris Augusti (Urso, CIL II2/5, 1033); Pontifex Caesaris primus (Ossigi, CIL II2/7, 4); flamen Augusti (CIL II2/7, 144).

52. CILA 3, 383: L(ucius) B[la]ttius L(uci) f(ilius) Traianus Pollio C(aius) T[raiu]s (?) C(ai) / f(ilius) Pollio IIvir(i) desig(nati) iter(um) pontific(es) prim[i cr]eati / Augusto orchestram pros[caeni]um itinera aras 
Asimismo, Andreu ha mostrado para el caso lusitano cómo los notables locales que ocuparon los sacerdocios de culto imperial en los centros cívicos desarrollaron el fenómeno de la munificentia, a través del cual se «compite por ganar merita aumentando la honorabilidad propia y de su entorno familiar» mientras que la comunidad «se beneficia de dicha competitividad $»^{53}$. La entrega de dinero, el reparto de grano, la concesión de ludi o la construcción y restauración de obras públicas constituían su acción evérgética que materializaba, en última instancia, la benefacción del princeps sobre los habitantes de su Imperio. Además de un medio de consolidación para las aristocracias locales, la veneración de los emperadores conformó una herramienta de promoción hacia el flaminado provincial.

Los grupos de notables que tenían una posición intermedia entre el poder central y la comunidad cívica fueron los que más se beneficiaron del ordenamiento que instituyó Augusto ${ }^{54}$. La administración imperial necesitaba contar con la élite local para que sus cuadros administrativos funcionasen, pero al mismo tiempo la nueva estructura permitía promocionar a sus miembros más allá de su comunidad de origen ${ }^{55}$. Como resultado, la élite cívica fue la primera en tomar las nuevas formas culturales y materiales que plasmaban la transformación de las urbes ${ }^{56}$. En este sentido, parece que el culto a la familia imperial que promovieron refleja su deseo de participar en el sistema romano que les beneficiaba.

\subsection{El culto imperial provincial en las capitales hispanas: estado de la cuestión}

De acuerdo con la información, principalmente, literaria y epigráfica se constata la existencia de una organización de culto imperial que superó el ámbito cívico. Dion Casio informa de las medidas tomadas por Augusto en el año 29 a. C. en Asia Menor, que supusieron el comienzo de la veneración de Divus Iulius, junto a la diosa Roma (en Éfeso y Nicea), y de él mismo (en Pérgamo y Nicomedia), tanto en Asia como en Bitinia ${ }^{57}$. Asimismo, las fuentes literarias también narran el inicio del culto federal de las Tres Galias en el 12 a. C. por iniciativa de

signa d(e) s(ua) / p(ecunia) $f$ (aciendum) c(uraverunt). Sobre el tercer miembro del colegio de los primeros pontífices del municipio italicense, véase CILA 3, 382: L(ucius) Herius L(uci) f(ilius) (duum)vir iter(um) (duum)virali / potest(ate) decr(eto) decur(ionum) tert(ia) pont(ifex) / creatus Augusto primus / municipio pollicitus ex / [p]atrimo[onio suo arc] us porticu[s] / [--- de sua] pecunia / [dedit idemq] ue dedicavit. Con respecto a la relación entre teatro y culto imperial, consúltese: P. Gros, "Théâtre et culte impérial en Gaule Narbonnaise et dans la Péninsule Ibérique”, en W. Trillmich y P. Zanker (coord.), Stadtbild und Ideologie die Monumentalisierung hispanischer Städte zwischen Republik und Kaiserzeit, 1990, 381-390.

53. J. Andreu, "Apuntes en torno al culto imperial y la conducta munificente de las élites en Lusitania", en Nogales y González (eds.), Culto... op. cit., 616.

54. G. Woolf, “The formation of Roman provincial cultures”, en J. Metzler et al. (eds.), Integration in the Early Roman West: The Role of Culture and Ideology, Luxemburgo, 1995, 12.

55. G. Woolf, "Beyond Roman and natives”, World Archeology, 28, 3, 1997, 346.

56. Woolf, “The formation..., op. cit. 12.

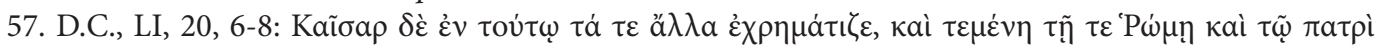

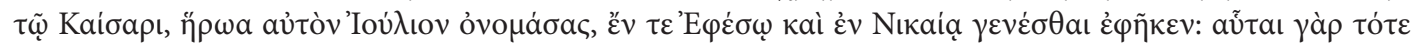

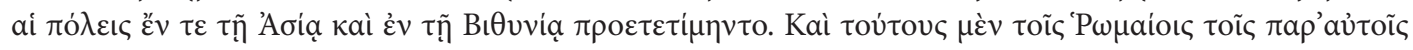


Druso. Su sede se localizó en el Altar de Augusto y Roma de Lugdunum (Lyon), al que acudían periódicamente los representantes de las comunidades de las Tres Galias que constituían su asamblea federal ${ }^{58}$.

La epigrafía de la Península Ibérica documenta la existencia de sacerdotes de culto imperial cívicos, conventuales y provinciales ${ }^{59}$. Estos últimos han sido objeto de estudio en numerosas publicaciones debido a su importancia para el conocimiento del comienzo de la organización del culto imperial provincial en Hispania, pues como se ha expuesto con anterioridad, la veneración del princeps en el ámbito local se inició en época augustea.

En el caso lusitano se constata la existencia de flamines provinciae desde época julioclaudia, pero los primeros testimonios de la Tarraconense y la Bética tienen una cronología flavia. Por otro lado, Tácito recoge en sus Annales la solicitud que realizan los hispani de la Tarraconense a Tiberio para levantar un templo a Divus Augustus en el año 15 d. C., así como la autorización que le demandan una serie de legati procedentes de la Ulterior Baetica en el año 25 d. C. para construir un templo dedicado a él mismo y a su madre Livia en esta provincia. Teniendo en cuenta el permiso del emperador en el primer caso y su negativa en el segundo, actualmente se propone una cronología julio-claudia para el comienzo de la organización supra-cívica de la veneración de la domus imperatoria en la Tarraconense y la Lusitania, y una datación flavia en la Bética. No obstante, a la compleja reconstrucción histórica del proceso hay que unir los últimos testimonios arqueológicos.

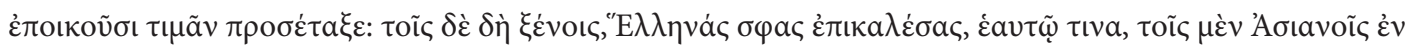

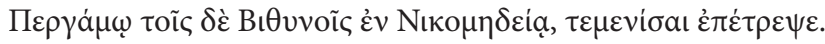

58. Las fuentes literarias que aportan información al respecto son: Dio Cass. LIV, 32, 1, y Suet. Claud. 2, 1. Véase también: Liv. Per. 139.

59. Consúltese sobre la organización conventual: B. Goffaux, "Priests, conventus and provincial organisation in Hispania citerior", en J.H. Richardson y F. Santangelo (eds.), Priests and State in the Roman World, Stuttgart, 2011, 445-469. Con respecto a la organización sacerdotal del culto imperial en Hispania es especialmente útil el trabajo de González Herrero: M. González Herrero, "La organización sacerdotal del culto imperial en Hispania", en Andreu, Cabrero e Rodà (eds.), Hispaniae... op. cit., 439-452. Sobre los sacerdotes provinciales, consúltense: Étienne, Le culte... op. cit., 121-175; Fishwick, The Imperial... op. cit., III, 2, 73-125, 139-154, y 215-247; S. Panzram, "Los flamines provinciae de la Bética: autorepresentación y culto imperial", Archivo Español de Arqueología, 76, 121-130; González Herrero, La implantación... op. cit., 1-52; J.A. Delgado, Élites y organización de la religión en las provincias romanas de la Bética y las Mauritanias: sacerdotes y sacerdocios, Oxford, 1998; J.A. Delgado, "Flamines provinciae Lusitaniae", Gerión, 17, 1999, 433461; G. Alföldy, Flamines provinciae Hispaniae Citerioris, Madrid, 1973; y Mª.C. Gregorio, "Flaminicae sive sacerdotes de la Provincia Hispania Citerior: el sacerdocio femenino del culto imperial", Hispania Antiqua, 37-38, 2013/2014, 137-163; C. Castillo García, "Los flamines provinciales de la Bética", Revue des Études Anciennes, 100, 1998, 437-460; y C. Castillo García, "Los flamines provinciales. El caso de la Bética", Élites y promoción social en la Hispania romana, Pamplona, 1999, 201-218. 


\section{Tarraco}

Como se ha adelantado con anterioridad, Tácito informa del permiso que Tiberio concedió a los hispani en el año 15 d. C. para construir un templo en Tarraco a su padre Augusto después de que hubiese sido divinizado en Roma tras su defunción: Templum ut in colonia Tarraconensi strueretur Augusto petentibus Hispanis permissum, datumque in omnis provincias exemplum ${ }^{60}$.

Actualmente se acepta el carácter «provincial» de dicho espacio sacro de acuerdo con la necesidad de una autorización imperial para emprender la obra, la iniciativa de los «hispanos» (no de los colonos de Tarraco) para elevar la solicitud, así como la noticia sobre el ejemplo que supuso para el resto de provincias. El destinatario de tal veneración sería Divus Augustus y la imagen de su recinto sagrado se ha puesto en relación con unas series monetales, de época tiberiana, que presentan en sus reversos un templo octástilo acompañado de la leyenda C(olonia) U(rbs) T(riumphalis) T(arraco) y Aeternitatis Augustae. El numerario posee dos tipos de anversos: Divus Augustus entronizado como Júpiter, con una victoria sobre globo y un cetro ${ }^{61}$, junto a la leyenda Deo Augusto; y un segundo modelo en el que se muestra la cabeza radiada del emperador deificado denominado Divus Augustus Pater ${ }^{62}$.

La localización del templo -así como el altar del que da noticia Quintiliano- es uno de los temas que más ha preocupado en los estudios sobre Tarraco. Según el estado actual de la investigación, la hipótesis que se alza con más fuerza es la que localiza el recinto en la zona alta de la ciudad. Este espacio de la colonia sufriría una importante transformación urbana para dar paso a un complejo en terrazas -conformado por un témenos, una plaza de representación y un circo- que se situaría en el interior del perímetro de la muralla tardorrepublicana y que estaría inspirado en el modelo desarrollado en el Palatino -casa de Augustotemplo de Apolo, pórtico de las Danaides y circo Máximo ${ }^{63}$.

El templo, que se presupone octástilo -como muestran los numerarios-, períptero y, posiblemente, sine postico -si se acepta que se usó como modelo el de Mars Ultor de la capi-

60. Tac., Ann. I, 78. Sobre la Tarraco romana, véase: R. Mar et al., Tarraco. Arquitectura y urbanismo de una capital provincial romana. Vol. 1 y 2, Tarragona, 2015.

61. RPC 222. En una variante del numerario, Divus Augustus se muestra sentado en una silla curul, sosteniendo una pátera y un cetro: RPC 224.

62. RPC 219. En otra variante se muestra en el anverso la leyenda Ti(berius) Caesar Divi Aug(usti) F(ilius) Augustus y en el reverso el templo octástilo junto a la leyenda C(olonia) U(rbs) T(riumphalis) T(arraco) Aeternitatis Augustae: RPC 226. Consúltense otras noticias sobre el templo de Divus Augustus de Tarraco en: SHA. Hadr. 12, 3, y SHA. Sev. 3, 4.

63. J.M. Macias et al., "La construcción del recinto imperial de Tarraco (Provincia Hispania Citerioris)", Butlletí Arqueològic, V, 32, 2009, 431: «Un recinto de culto de 2 ha, a sus pies una gran plaza cívica de 6 ha, y separando el resto de la ciudad propiamente dicha, un circo de 4 ha que se adosaba a ambos laterales de la muralla». El famoso altar del que da noticia Quintiliano (Inst. 6, 3, 77), posiblemente se localizaría en el foro colonial, en la parte baja de la ciudad. Cabe destacar que, recientemente, se ha retomado la tesis que vincula el altar con la organización provincial: R. Mar et al., Tarraco..., op. cit., vol. 1, 344. Véase la crítica de Fishwick al respecto en: D. Fishwick, "Augustus and the cult of the Emperor", Studia Historica. Historia Antigua, 32, 2014, 57-60. 
tal-, se ubicaría en la parte alta del complejo ${ }^{64}$. Tras dicho templo, en el lado norte del pórtico que lo enmarca y en eje con él, se ha identificado una gran sala axial interpretada como aedes imperial o lugar de reunión del concilio provincial ${ }^{65}$.

El témenos comunica, a través de una escalinata monumental, con un espacio de representación que se extiende en un nivel inferior y que posiblemente acogería una serie de pedestales de estatuas relacionados con los flamines provinciae. Alföldy estudió un notable conjunto epigráfico en el que aparecía como dedicante el concilium de la provincia homenajeando a flamines provinciae, emperadores o miembros de su domus y personajes destacados de la administración provincial. De acuerdo con su trabajo, actualmente se considera que el complejo en terrazas de Tarraco fue la sede del Concilium Provinciae Hispaniae Citerioris ${ }^{66}$.

El principal problema que plantea el estudio del conjunto es cronológico, ya que la cita de Tácito y las acuñaciones tiberianas no casan completamente con los datos arqueológicos de comienzos de época flavia ${ }^{67}$. La intensa prospección geofísica que se ha llevado a cabo en el interior de la catedral ha permitido identificar una plataforma de opus caementicium sobre la que se plantea que apoyaría la cimentación del templo; sin embargo, no se dispone

64. J.M. Macias et al., "El templo de Augusto en Tarraco: últimas excavaciones y hallazgos", XVIII Congreso Internacional Arqueología Clásica. Centro y periferia en el Mundo Clásico (Mérida, 2013), vol. 2, Mérida, $2014,1542$.

65. Véanse las últimas interpretaciones al respecto en: Th. Hauschild, "Algunas observaciones sobre la construcción de la sala-aula situada detrás de la catedral de Tarragona”, Butlletí Arqueològic, V, 31, 2009, 313-344; y R. Mar, J. Ruiz de Arbulo y D. Vivó, "Los Genios de los conventus Iuridici y el lugar de reuniones del Concilium Provinciae Hispaniae Citerioris ¿Una curia de uso provincial en Tarraco?”, Anejos del Archivo Español de Arqueología, 67, 2013, 25-41. Hauschild señala que «la planta recuerda también a las Aedes Augusti, salas que resaltan de las basílicas de los foros como en Astorga y también en Tarragona. En nuestro caso podemos suponer una gran estatua del emperador como centro del culto, situado en el final del extenso eje de los grandes recintos en lo alto de Tarraco, proyectados en la época Flavia, como punto culminante para las ceremonias» (p. 322). Por su parte, Mar, Ruiz de Arbulo y Vivó proponen la ubicación de un ciclo icónico de los genii de los conventus jurídicos en la sala axial, lo que les permite proponer que fuera el lugar de reunión del Concilium Provinciae Hispaniae Citerioris.

66. Los estudios de Hauschild definieron, en un primer momento, el complejo: Th. Hauschild, Arquitectura romana de Tarragona, Tarragona, 1983. Para las últimas aportaciones, véase: J.M. Macias et al., Planimetría Arqueológica de Tarraco, Tarragona, 2007. La documentación epigráfica que estudia Alföldy se extiende desde el año 70 a finales del siglo II: Alföldy, Flamines... op. cit. Véase al respecto: CIL II2/14, 1109-1199. Consúltese sobre un nuevo testimonio de flamen provincial: A. Peña et al., "Más datos sobre el templo del Divus Augustus de Tarraco: a propósito de una nueva inscripción”, en J. López Vilar (ed.), Tarraco Biennal (Actes). 2on congrés internacional d’arqueologia i món antic. August i les províncies occidentals. 2000 aniversari de la mort d’ August. Tarragona, 26-29 de noviembre de 2014, Tarragona, 2015, 181-189. Sobre la denominación del conjunto como «Foro Provincial», véase: J. Ruiz de Arbulo, “Tarraco. Escenografía del poder, administración y justicia en una capital provincial romana (s. II a. C. - II d. C.)”, Empúries, 51, 1998, 52 , con nota 123 con bibliografía sobre la opinión que ha generado el uso de esta denominación (vid. infra).

67. Macias et al., "La construcción..., op. cit. 431-432. 
de estratigrafía constructiva ${ }^{68}$. Los análisis que se han realizado de los contexto ceramológicos proponen una cronología flavia ${ }^{69}$ y los primeros epígrafes de los flamines provinciae son posteriores al año $70 \mathrm{~d}$. C., por lo que no han faltado planteamientos que ubican el templo de Divus Augustus en el foro colonial de la ciudad ${ }^{70}$.

Desde el año 2000 hasta la actualidad, la recuperación de elementos de decoración arquitectónica ${ }^{71}$ y los resultados de las excavaciones del Plan Director de la Catedral de Tarragona centran el discurso interpretativo en la definición de dos procesos constructivos consecutivos que comprenden cronológicamente «la fecha de la embajada tarraconense ante Tiberio (15 d. C.) y las dataciones de época flavia que se aplican a la construcción y/o utilización del Concilium Provinciae». De este modo, se plantea que pudo existir una voluntad de monumentalización, que comenzaría en época julio-claudia, y una ampliación o reformulación posterior del proyecto $^{72}$, aunque actualmente se desconoce el motivo de la modificación, así como el grado de finalización del primero:

68. En cuanto a las últimas aportaciones sobre el conocimiento del templo de culto, véase: J.M. Macias et al., "Arqueologia a la nau central de la Catedral de Tarragona", Tribuna d' Arqueologia, 2010-2011, 151173; y Macias et al., "El templo...”, op. cit. 1539-1543. Sobre los resultados de las prospecciones geofísicas en el subsuelo de la catedral, consúltese: A. Casas et al., "Integrated archeological and geophysical survey forsearching the roman's Augustus Temple in Tarragona (Spain)", Scienza e Patrimonio Culturale nel Mediterraneo. Diagnostica e conservazione. Esperienze e Proposte per una Carta del Rischio, I Quaderni di Palazzo Montalbo, 15, Palermo, 2009, 273-283. Para una aproximación a las medidas del templo a partir de la decoración arquitectónica, véase: P. Pensabene y R. Mar, "Il tempio di Augusto a Tarraco. Gigantismo e marmo lunense nei luogui di culto imperiale in Hispania e Gallia”, Archaelogia Classica, 61, 11, 2010, Roma, 243-308. Sin embargo, la dimensión que proponen Pensabene y Mar se han considerado excesivas: Macias et al., "El templo..., op. cit. 1542.

69. X. Aquilué, La seu del Collegi d’Arquitectes. Una intervenció arqueológica en el centre històric de Tarragona, Tarragona, 1993; X. Aquilué, “Arquitectura oficial”, en X. Dupré (ed.), Tarragona. Colonia Iulia Vrbs Triumphalis Tarraco, Las capitales provinciales de España, 3, Roma, 41-53; y TED’A (Taller Escolar d'Arqueologia), "El foro provincial de Tarraco. Un complejo arquitectónico de época Flavia”, Archivo Español de Arqueología, 62, 1989, 141-191.

70. J. Ruiz de Arbulo, "El altar y el templo de Augusto en la colonia Tarraco. Estado de la Cuestión”, J. M. Noguera (ed.), Fora Hispaniae. Paisaje urbano, arquitectura, programas decorativos y culto imperial en los foros de las ciudades hispanorromanas, Murcia, 2009, 182: «Creemos por tanto, mucho más factible que el nuevo templo de Augusto tuviera también que situarse, al igual que el altar en el foro de la colonia».

71. P. Pensabene y R. Mar, "Dos frisos marmóreos en la acrópolis de Tarraco, el templo de Augusto y el complejo provincial de culto imperial”, en J. Ruiz de Arbulo (ed.), Simulacra Romae. Roma y las capitales provinciales del Occidente Europeo. Estudios Arqueológicos, Tarragona, 2004, 73-86.

72. Véase sobre la cita y la interpretación: J.M. Macias et al., "La acrópolis de Tarraco y la implantación urbana del culto imperial en la capital de la Hispania Citerior", XVII International Congress of Classical Archaeology, Roma 22-26. 2008, 2011, 53-54. Con respecto a la hipótesis de dos procesos constructivos consecutivos, tanto los trabajos sobre la arquitectura decorativa elaborados por Pensabene y Mar como el estudio arqueológico de Macias, Menchon, Muñoz y Teixell apuntaban a esta opción. Ciertamente, Pensabene y Mar identificaron dos tipos de frisos: en primer lugar, uno de roleos que se fecha en época julio-claudia y que se atribuye al templo de Divus Augustus y, en segundo lugar, otro friso decorado con bucráneos, guirnaldas e instrumentos sacerdotales con una cronología de inicios del período Flavio, que se

Revista de historiografía 28, 2018, pp. 183-212 
Las extraordinarias dimensiones del conjunto nos hacen pensar en una obra de factura dilatada. La terraza superior pudo iniciarse a mediados del siglo I d. C. y finalizarse en época Flavia. La terraza media o plaza de representación sería, a falta de más datos, una obra plenamente de cronología Flavia [...] Finalmente, a finales del siglo I d. C. el conjunto se cierra con la construcción de un gran circo que separaba este complejo imperial de la ciudad propiamente dicha ${ }^{73}$.

Asimismo, a medida que avanza la investigación arqueológica sobre el témenos del complejo aumentan sus semejanzas con el recinto sacro del Forum Pacis, inaugurado en el año 75 d. C. ${ }^{74}$.

\section{Corduba}

A diferencia de lo que se propone para la Lusitania y la Tarraconense, la mayor parte de los investigadores que analizan el comienzo de la organización supra-cívica de culto imperial en la Bética plantean una cronología flavia ${ }^{75}$. Se sigue, por tanto, la tesis de Étienne: «Le fait capital pour le culte impérial en Bétique, province sénatoriale, c'est qu'il a été fondé par Vespasien ${ }^{76}$.

Fishwick ha argumentado esta hipótesis por extenso. Según sus estudios, territorios como la Bética, la Galia Narbonense y el África Proconsular, presentan los primeros testimo-

pone en relación con la sala axial del pórtico septentrional de la plaza en la que se incluye el templo. Véase sobre el estudio de los materiales: P. Pensabene y R. Mar, "Dos frisos...”, op. cit., 73-86. Consúltese también: J.M. Macias et at., La Catedral de Tarragona, Tarragona, 2007, 160-165.

73. Macias et al., "La acrópoli..., op. cit., 58-59. La decoración que se propone para el friso del pórtico del peribolos es una sucesión de clipei de Júpiter-Amón que probablemente se alternasen con otros de Medusa, separados entre ellos por candelabros vegetales. Véase: J. M. Macias et al., "Nuevos elementos arquitectónicos del recinto de culto del Concilium Provinciae Hispaniae Citerioris (Tarraco, Hispania Citerior)", en T. Nogales e I. Rodà (eds.), Roma y las provincias: modelo y difusión, vol. II, Roma, 2011, 192. Así, parece que pierde fuerza la hipótesis sobre el uso de cariátides para separar los clipei, siguiendo como ejemplo el Forum Augustum: J.M. Macias et al., "Excavaciones en la ciudad de Tarragona y en su entorno: Avances y retrocesos en la investigación sobre el culto imperial", en Nogales y González (eds.), Culto... op. cit., 780; y Macias et al., "Nuevos elementos...", op. cit., 194. En cuanto a su cronología, Koppel consideró que un primer grupo de clipei podían ser datados en época julio-claudia (E. M. Koppel, "Relieves arquitectónicos de Tarragona", en Trillmich y Zanker (eds.), Stadtbild... op. cit., 339), por lo que se ha propuesto que la decoración arquitectónica fuera elaborada mientras se erigía la obra, con varios tramos constructivos que se desarrollarían con anterioridad al gobierno de los Flavios (Macias et al., "Nuevos elementos...", op. cit., 193194). Cabe destacar el empleo, principalmente, de mármol de Luni-Carrara en el área sacra -tanto en los paramentos interiores de los muros de los pórticos como en las columnas y los frisos (Macias et al., "Nuevos elementos...", op. cit., 189). Véase también: F. Marco Simón, "Iconografía y propaganda ideológica. Júpiter Amón y Medusa en los foros imperiales", en J.M. Croisille (ed.), Neronia IV. Alejandro Magno, modelo de los emperadores romanos, Bruselas, 1990, 143-162.

74. Macias et al., "La construcción...", op. cit., 438-439.

75. Véase por conveniencia: Fishwick, The Imperial... op. cit., I, 2, 239; Delgado, Élites... op. cit., 44; y González, "El origen...”, op. cit., 175.

76. Étienne, Le culte... op. cit., 130. 
nios de culto imperial provincial durante el gobierno de los Flavios; sin embargo, su tesis ha recibido algunas críticas, ya que ciertos autores proponen la posibilidad de una organización en época julio-claudia. Hace algunos años, Le Roux y Castillo García ya mostraron sus dudas sobre la interpretación tradicional. Actualmente, se suman las valoraciones, principalmente, de Garriguet y González Herrero ${ }^{77}$.

Como ya se ha expuesto con anterioridad, Tácito informa de la solicitud a Tiberio, por parte de una serie de legati procedentes de la Hispania Ulterior, sobre la construcción de un templo consagrado a su persona y a su madre Livia en el año $25 \mathrm{~d}$. C.; una petición que no recibió el beneplácito del emperador: Per idem templus Hispania ulterior missis ad senatum legatis oravit, ut exemplo Asiae delubrum Tiberio matrique eius exstrueret ${ }^{78}$.

Por otro lado, de acuerdo con la información epigráfica y arqueológica se han interpretado determinadas áreas de la capital provincial como zonas de representación imperial que se han puesto en relación con el culto a la domus imperatoria. Éstas son el forum adiectum que se anexó al sur del denominado «foro de la colonia», el entorno del actual área conocida como Altos de Santa Ana y el complejo en niveles de las calles Claudio Marcelo y Capitulares $^{79}$. Actualmente se barajan diferentes hipótesis sobre la existencia, en estos tres espacios, de al menos dos templos vinculados al culto imperial; uno dedicado a Divus Augustus en el forum adiectum en período tiberiano, y otro consagrado a Divus Claudius en la calle Claudio Marcelo, que se iniciaría posiblemente en época neroniana temprana y que se concluiría durante el gobierno de los Flavios. En este sentido, existe un debate entre los investigadores con el objetivo de determinar si alguno de los dos recintos acogió los rituales de culto imperial de la provincia, así como la sede del concilium.

77. P. Le Roux, “Lévolution du culte impérial dans les provinces occidentales d'Auguste à Domitien”, Pallas, 40, 1994, 397-411; C. Castillo García, "Los flamines provinciales de la Bética”, Revue des Études Anciennes, 100, 1998, 438; J.A. Garriguet, El culto imperial en la Córdoba romana: una aproximación arqueológica, Córdoba, 2002, 162, 164, 166-167; y González Herrero, La implantación... op. cit., 111.

78. Tac. Ann. IV, 37, 1.

79. En el foro de la colonia se hallaron dedicaciones sobre pedestales -acompañadas de la fórmula devotus numini maiestatique - dirigidas a los emperadores Galieno y Valeriano (CIL II2/7, 257), Constancio Cloro (CIL II2/7, 261) y Constantino II (CIL II2/7, 264), así como basas de estatuas levantadas en honor a determinados flamines provinciales (dedicadas por el ordo de los decuriones de Corduba (CIL II2/7, 282, y CIL II2/7, 296) y el ordo Malacitanorum (AE 1996, 883). En el área conocida como Altos de Santa Ana, se ubicaría otra plaza pública que, según Stylow, sería la sede del concilium de la Bética. Uno de sus argumentos fue el hallazgo de varias inscripciones que documentan homenajes a flamines provinciae Baeticae en el sector, con una cronología de mediados del siglo II y comienzos del siglo III: CIL II2/7, 291; CIL II2/, 7, 292; CIL II2/, 7, 295, y CIL II2/, 7, 297. Véase al respecto: A.U. Stylow, "Apuntes sobre el urbanismo de Córdoba romana”, en Trillmich y Zanker (eds.), Städtbild... op. cit., 274-279. Sobre la posible existencia de un área sacra o Augusteion en esta parte de la ciudad, consúltese: P. León, "Itinerario de monumentalización y cambios de imagen en Colonia Patricia (Córdoba)", Archivo Español de Arqueología, 72, 1999, 39-56; J.A. Garriguet, "Reflexiones en torno al denominado 'Foro de Altos de Santa Ana' y al comienzo del culto dinástico en Colonia Patricia Corduba”, Anales de Arqueología Cordobesa, 10, 1999, 87-113; y Garriguet, El culto imperial... op. cit., 127-128. 
Al suroeste del foro colonial, entre las calles Morería e Historiador Díaz del Moral, se ubicaría el denominado forum novum o adiectum ${ }^{80}$. A través de un estudio de restos de decoración arquitectónica procedentes de la calle Morería y recuperados a lo largo del siglo XX, Márquez planteó la existencia de un templo edificado en mármol de dimensiones colosales y un altar, ambos integrados en el interior de un espacio porticado ${ }^{81}$. Posteriormente, con las intervenciones arqueológicas emprendidas en el número 5 de dicha calle se localizó una cimentación de opus caementicium, un tambor de fuste de columna y otros elementos de ornamentación que se pusieron en relación con este recinto sagrado, datado en época tardo-augustea/tiberiana ${ }^{82}$. De acuerdo con la reconstrucción arquitectónica de quienes han estudiado el recinto, se plantea la existencia de un templo octástilo, períptero, sine postico y de orden corintio que seguiría el modelo del de Mars Ultor de la Urbs $s^{83}$ y del programa escultórico del Forum Augustum ${ }^{84}$.

80. Sobre las dimensiones de la plaza, véase: A. Peña, Á. Ventura y A. Portillo, "El templo consagrado a Divo Augusto y su temenos (Forum Novum)", Córdoba, reflejo de Roma, 2011, 63-64. Es interesante destacar que de las inmediaciones de este área proceden una basa dedicada a un flamen provinciae, datada a finales del siglo II (CIL II2/7, 293), y otra que homenajea a Filipo el Árabe con la fórmula devota numini maiestatique eius, fechada en el año 245 (CIL II2/7, 255). Ambas estatuas fueron concedidas por el concilium de la Bética.

81. C. Márquez, La decoración arquitectónica de Colonia Patricia. Una aproximación a la arquitectura y el urbanismo de la Córdoba romana, Córdoba, 1998, 176-178. Se ha considerado que el edificio estaría alineado con el decumano máximo, orientado a poniente e incluido en una plaza rodeada por una porticus triplex - en sus lados meridional, septentrional y oriental-, a la que se accedería por su parte occidental. Véase: A. Portillo, "Estudio arquitectónico del templo de la calle Morería en el Forum Novum de Colonia Patricia”, en J. López Vilar (ed.), Tarraco Biennal... op. cit., 75, con nota 5. Consúltese el trabajo de Portillo para una detallada reconstrucción arquitectónica del edificio. Véase, también, sobre el templo del forum novum: Peña, Ventura y Portillo, "El templo...", op. cit., 59-67. Recientemente, Portillo ha planteado la posibilidad de la restauración del edificio, o al menos parte del mismo, en un momento indeterminado de la primera mitad del siglo II: A. Portillo, "Una posible restauración del templo de la calle Morería en el forum novum de Colonia Patricia en el siglo II", Anales de Arqueología Cordobesa, 25-26, 2014-2015, 71-82.

82. I. Carrasco y R. García, "Hallazgos en el n 5 de la calle Morería y un nuevo espacio público de Colonia Patricia", Anales de Arqueología Cordobesa, 15, 2004, 145-172. Después de su trabajo de 1998, Márquez publicó otras piezas pertenecientes al recinto: C. Márquez, "La decoración arquitectónica en Colonia Patricia en el periodo julioclaudio", en S. Ramallo (ed.), La decoración arquitectónica de las ciudades romanas de occidente, Actas del Congreso Internacional (Cartagena 8-10 octubre de 2003), Murcia, 2004, 337-353; y C. Márquez, "Baetica templa", en J. Ruiz de Arbulo (ed.), Simulacra Romae. Roma y las capitales del Occidente Europeo, Tarragona, 2004, 109-127. Sobre su cronología, véase: C. Márquez et al., "Estudio de materiales de la excavación arqueológica en calle Morería”, Anuario Arqueológico de Andalucía, 2001, 1, 123-134.

83. Márquez, "Baetica..., op. cit., 110, 112-113, 125.

84. Se propone una fachada de $29,6 \mathrm{~m}$. de anchura y con una altura total de circa $30 \mathrm{~m}$. Véase: Portillo, "Estudio arquitectónico..., op. cit., 77-78; y Peña, Ventura y Portillo, “El templo..., op. cit., 60-61. En dicho programa se incluiría el torso de 1,90 m perteneciente a una estatua loricata -procedente de la colección Tienda- y que Trillmich identificó con el Eneas del grupo escultórico de aquel foro de la capital imperial (W. Trillmich, "Los tres foros de Augusta Emerita y el caso de Corduba", en P. León (ed.), Colonia Patricia Corduba: una reflexión arqueológica (Córdoba 1993), Sevilla, 1996, 175-195); un pie con mulleus que se ha puesto en relación con la representación de un rey mítico; once togati procedentes de la Ronda de los Tejares 
Ventura estableció por primera vez la hipótesis de que el templo de la calle Morería estuviera consagrado a Divus Augustus. Según la propuesta del autor, el edificio se construyó con el permiso de Tiberio que, tras la negativa a los legati procedentes de la Hispania Ulterior para erigir un templo consagrado a él mismo y a su madre, accedió a la elevación de un espacio de culto dedicado a Divus Augustus que contó con su patrocinio ${ }^{85}$. El recinto, en su opinión, podría constituir el espacio de culto imperial de la provincia, al menos hasta época flavia -teniendo en cuenta la existencia del templo de la calle Claudio Marcelo (vid. infra) - y estaría conectado con el anfiteatro en las fiestas en honor a la domus Augusta ${ }^{86}$.

El segundo recinto sacro que se ha vinculado con el culto imperial provincial es el complejo monumental en terrazas que fue organizado topográficamente en tres grandes niveles, aunque para algunos investigadores concebido posiblemente de manera unitaria ${ }^{87}$. Edificado en el extremo oriental de la urbe, ocupó una posición excéntrica y estuvo conformado por un templo (calle Claudio Marcelo), la llamada «terraza intermedia» (calle Capitulares) y un circo (en la «manzana de Orive $»)^{88}$. El templo -incluido en una plaza de tendencia rectangular y porticada por sus extremos Norte, Sur y Oeste- estaría orientado a Oriente -donde se disponía el resto del conjunto monumental- y sería próstilo, pseudoperíptero, hexástilo y de orden corintio ${ }^{89}$.

y que pudieron configurar una galería de summi viri (I.Ma. López, Estatuas masculinas togadas y estatuas femeninas vestidas en colecciones cordobesas, Córdoba, 1998, 43-52, nº 14-24); e imágenes de emperadores de acuerdo con la información epigráfica (CIL II2/7, 255 y CIL II2/7, 258).

85. De acuerdo con el empleo de gran cantidad de mármol de Luni: Márquez, La decoración... op. cit., 177.

86. El autor basa su argumentación en el hallazgo de dos fragmentos de mármol de Luni con mortajas, para integrar litterae aureae, que se descubrieron en la intervención arqueológica realizada en el Paseo de la Ribera (no 4): Á. Ventura, "Reflexiones sobre la arquitectura y advocación del templo de la calle Morería en el forum adiectum de Colonia Patricia Corduba”, en Nogales y González (eds.), Culto... op. cit., 215237. Consúltese también al respecto: D. Fishwick, "The temple on the New Forum of the Corduba and the Provincial Centre of Hispania Ulterior", Latomus, 73, 2014, 661-666.

87. D. Vaquerizo, J.F. Murillo y J.A. Garriguet, "Novedades de arqueología en Corduba, Colonia Patricia", en J. González y J.C. Saquete (eds.), Colonias de César y Augusto en la Andalucía romana, Roma, 2011, 24.

88. Sobre las últimas intervenciones que han tenido lugar entre 2001 y 2003, véanse: J.F. Murillo et al. " $\mathrm{El}$ templo de la c/Claudio Marcelo (Córdoba). Aproximación al foro provincial de la Bética", Romula, 2, 2003, 53-88; y J.L. Jiménez, "El templo romano de Córdoba", en J. Blánquez y M. Pérez (eds.), Antonio García y Bellido y su legado a la Arqueología Española (1903-1972), Serie Varia, 5, Madrid, 2004, 159-171.Consúltese también: Fishwick, The imperial... op. cit., III, 3, 90-98.

89. La cimentación del templo alcanzaba $31,27 \mathrm{~m}$. de longitud, 14, $72 \mathrm{~m}$. de anchura y una altura estimada de 17-18 m. Sobre sus características, consúltese: J.A. Garriguet, "Sobre el modelo, cronología y posible dedicación del templo romano de C/ Claudio Marcelo, Córdoba. Apuntes arqueológicos e históricos", Arys, 12, 2014, 244-245. El material utilizado en la decoración arquitectónica fue mármol blanco de Luni y de las canteras hispanas (Almadén-Estremoz). El estudio estilístico que desempeña Márquez proporciona una cronología del tercer cuarto del siglo I: C. Márquez, Capiteles romanos de Cordoba Colonia Patricia, Córdoba, 1990, 188-191. 
A pesar de la ausencia epigráfica que determine su advocación y de inscripciones que hagan referencia al concilium, no han faltado los argumentos para vincular el recinto sacro con el culto imperial provincial ${ }^{90}$. Su posición escenográfica no pasa desapercibida a los ojos de los investigadores y la estructura en tres niveles (templo, terraza, circo) ha hecho establecer paralelismos con el complejo en terrazas de Tarraco $^{91}$.

Recientemente, Garriguet ha dado un paso más en la interpretación. El autor ha propuesto que el templo de la calle Claudio Marcelo estuviera dedicado a Divus Claudius, edificado en época neroniana temprana (54-60 d. C.) y finalizado durante el período flavio. El estudioso basa su hipótesis en su modelo arquitectónico y ornamental, estableciendo las similitudes del recinto cordobés con el de Apolo, construido por Augusto en el Palatino, y el de Divus Claudius en la Vrbs ${ }^{92}$.

\section{Augusta Emerita}

Se propone también una cronología julio-claudia para el caso de Lusitania. A pesar de que las fuentes literarias no mencionan de qué modo se desarrolló la iniciativa a través de la cual comienza la organización de un culto imperial provincial en el territorio, existen testi-

90. García y Bellido destacó la similitud del templo de la calle Claudio Marcelo, tanto de su planta como de su ornamentación arquitectónica y dimensión, con el dedicado en la colonia de Nemausus (Nîmes), la Maison Carrée, a los nietos de Augusto, Lucio y Gayo. Por otro lado, Jiménez Salvador consideró que la localización del edificio extramuros - para cuya elevación se había tenido que amortizar la muralla republicana de la ciudad-, alzado sobre potentes rellenos que le hacían dominar su entorno y presidiendo una plaza porticada, favorecía su relación con el culto dinástico. Consúltese al respecto: A. García y Bellido, "Crónica de Arte y Arqueología. El templo romano de Córdoba", Boletín de la Real Academia de Córdoba, 81, 1961, 213-217; y J.L. Jiménez Salvador, "La multiplicación de plazas públicas en la ciudad hispanorromana", Empúries, 51, 1998, 18.

91. Garriguet, "La decoración escultórica del templo romano de las calles Claudio Marcelo-Capitulares y su entorno (Córdoba). Revisión y novedades", en Nogales y González (eds.), Culto... op. cit., 302. Así, se ha propuesto que este espacio conformara la sede del concilium de la Bética o, al menos, se ha planteado su uso en las ceremonias de culto imperial a nivel provincial: León, "Itinerario..., op. cit., 50; Garriguet, El culto imperial... op. cit., 167-168; Murillo et al., "El templo..., op. cit., 84; Jiménez Salvador, "El templo..., op. cit., 168-169; Á. Ventura, "Edificios de espectáculos", en X. Dupré (ed.), Las capitales provinciales de Hispania. 1. Córdoba, Colonia Patrica Corduba, Roma, 74 y s.; Garriguet, "La decoración..., op. cit., 318; C. Márquez, “Templos", en P. León (coord.), Arte romano de la Bética. Arquitectura y Urbanismo, Sevilla, 2008, 137-141; y Garriguet, "Sobre el modelo...", op. cit., 247. Frente a esta opinión, véase: Panzram, “Los flamines..., op. cit., 125. Consúltese el estudio de la decoración escultórica en: Garriguet, “La decoración...”, op. cit., 299-321.

92. Garriguet, "Sobre el modelo...", op. cit., 238-267. El templo de Divus Claudius de Roma fue próstilo, pseudoperíptero, corintio y posiblemente hexástilo (p. 258). La propuesta de Garriguet concuerda cronológicamente con la información obtenida a través de las intervenciones arqueológicas en la calle Claudio Marcelo y su entorno que remiten constantemente a una datación claudio-neroniana, al igual que si se atiende a la decoración arquitectónica, pues según los trabajos de Márquez ésta se debe situar en torno a los años 60 del siglo I. 
monios de flamines provinciae desde ese período $^{93}$. Se plantea, por tanto, que en un primer momento el beneficiario de la veneración fuera Divus Augustus -como ocurriría en Tarraco-, al que se sumaría posteriormente Diva Augusta en el año 41 d. C. tras su deificación por iniciativa de su nieto Claudio ${ }^{94}$.

El edificio que acogería en un principio los rituales en su honor, oficiados por los flamines provinciae, se ha querido ver en una serie de numerarios emeritenses, acuñados durante el gobierno de Tiberio -como en el caso de Tarraco-, en los que aparece un templo tetrástilo con la leyenda Aeternitatis Augustae y dos tipos de anversos: el primero muestra la cabeza radiada de Augusto divinizado y la leyenda Divus Augustus Pater y, el segundo, el rostro de Tiberio laureado como pon(tifex) max(imus) e imp(erator) ${ }^{95}$.

Aunque la capital lusitana contaba con diferentes espacios que se han puesto en relación con el culto imperial -de manera hipotética como en el caso del templo de Diana y del denominado forum adiectum, o gracias a la información epigráfica como en el sacrarium del teatro ${ }^{96}$-, sólo los restos arqueológicos y arquitectónicos del edificio hallado en la calle Holguín se han vinculado con un posible templo dedicado por la provincia, probablemente, para la veneración de Divus Augustus. No obstante, la ausencia de pruebas definitivas que permitan atribuir un uso provincial al área, así como la inexistencia de testimonios que determinen la advocación del templo, ha favorecido el debate entre los historiadores.

Las intervenciones arqueológicas desarrolladas desde comienzos del siglo XXI han permitido avanzar en el conocimiento del edificio de la calle Holguín y en el conjunto monu-

93. Concretamente, según González Herrero, L. Cornelius L. f. Gal. Bocchus ocupó el flamonium en época tiberiana, L. Cornelius C. f. Bocchus en algún momento del período julio-claudio, L. Papirius L. f. probablemente con anterioridad al año 42, Albinus Albuif. en una fecha cercana al año 42 y Aponius Capito en el 48. Consúltense sobre los sacerdotes: González Herrero, La implantación... op. cit., 1-3, 4-6, 9-14, 1428 y $36-37$.

94. Así se constata en los títulos de los flamines provinciae: flamen D[ivi Augusti et] Divae Aug(ustae) provinciae Lusitan[iae dedicavit]; y [fla]men provinc[iae Lusita]niae Divi Aug(usti) [et?] Divae Aug(ustae). Sobre la restitución del título del primer flamen, véase: J. Edmondson, “Two dedications to Divus Augustus from Augusta Emerita and the early development of the impirial cult in Lusitania re-examined”, Madrider Mitteilungen, 38, 1997, 89-105. Con respecto al segundo, consúltese: González Herrero, La implantación... op. cit., 4-6.

95. RPC 29, 47 y 48.

96. El templo de Diana, localizado en el denominado foro colonial de la ciudad aunque sobreelevado en relación al mismo, fue construido en época augustea. Consúltese sobre el edificio: J. M. Álvarez y T. Nogales, Forum Coloniae Augustae Emeritae. 'Templo de Diana', 2 vol., Mérida, 2003. Con respecto al forum adiectum, que por su programa escultórico y su decoración arquitectónica refiere al Forum Augustum, véase: Álvarez y Nogales, Forum Coloniae... op. cit., 290 y s. con toda la bibliografía. En cuanto al foro en su conjunto, consúltese: R. Ayerbe, T. Barrientos y F. Palma, El foro de Augusta Emerita. Génesis y Evolución de sus recintos monumentales, Madrid, 2009. Véase la revisión de Trillmich sobre la vinculación del aula sacra del teatro, el templo de Diana y el forum adiectum con el culto imperial: W. Trillmich, "Espacios públicos de culto imperial en Augusta Emérita", en Nogales y González (eds.), Culto... op. cit., 420- 422 y 423-434. Sobre el sacrarium de época trajanea ubicado en el centro de la ima cavea, consúltese: W. Trillmich, "Un sacrarium de culto imperial en el teatro de Mérida”, Anas, 2-3, 1989-1990, 87-102.

Revista de historiografía 28, 2018, pp. 183-212 
mental en el que se enmarcaba. Actualmente se propone la existencia de una plaza delimitada por un pórtico, en al menos tres de sus lados -Norte, Este y Oeste-, a la que se ingresaba por su extremo sur a través de una puerta de tripe acceso -el denominado «Arco de Trajano». Además, adquiere fuerza la hipótesis que propone un templo hexástilo con una serie de columnas que rodearían el pronaos y una cella más ancha, dispuesta de manera trasversal en relación con el pronaos («cella barlonga») y cerrada mediante un muro corrido ${ }^{97}$. Así, mientras que algunos investigadores desvinculan el edificio con el representado en los numerarios de época tiberiana ${ }^{98}$, otros plantean la posibilidad de que las acuñaciones únicamente esbozaran un esquema de la empresa constructiva9.

Con respecto a su cronología, el estudio de su decoración arquitectónica proporcionó una datación de época tardoaugustea/tiberiana ${ }^{100}$, mientras que los materiales obtenidos en las excavaciones del pórtico que delimitaría el espacio en el que se incluyó el templo se fechan

97. Este espacio emeritense ha recibido el nombre de «foro provincial»-diferenciado claramente del colonial- como se pone de manifiesto en la última monografía dedicada al recinto: P. Mateos (ed.), El "Foro provincial" de "Augusta Emerita": un conjunto monumental de culto imperial (Anejos de Archivo Español de Arqueología, XLII), Madrid, 2006. No obstante, ya hace algunos años que Trillmich apuntó que la denominación «foro provincial» no fue una designación empleada por los romanos: W. Trillmich, "Foro provincial und Foro municipal in den Hauptstädten der drei hispanischen Provinzen: eine Fiktion", Ciudad y comunidad cívica en Hispania (Siglos II-III d. C), Madrid, 1993, 117 y s. Sobre las características del templo, consúltese: P. Mateos, "El templo: la traslación de los modelos metropolitanos a la capital de la provincia Lusitana", en P. Mateos (ed.), El "Foro...", op. cit., 251-276. En las últimas intervenciones arqueológicas desarrolladas en el año 2006 se documentó el límite meridional del pronaos, los restos de las escalinatas de acceso al templo y del anta oriental. Véase sobre este aspecto y las posibles dimensiones del edificio: Mateos, "El templo..., op. cit., 256. De acuerdo con las últimas investigaciones se constata la existencia de un pórtico que delimita el espacio y se observa la amortización de estructuras anteriores, tanto de un hábitat doméstico -cuatro manzanas de casas- como parte del cardo máximo, por lo que se plantea que la construcción del conjunto no fuera coetánea a la fundación de la ciudad. Con respecto al complejo monumental, tanto del pórtico, como del denominado «Arco de Trajano» y del templo, consúltense por conveniencia: P. Mateos, "El culto imperial en el llamado 'Foro de Provincial' de Augusta Emerita", en P. Mateos (ed.), El "Foro... op. cit., 315-354; y P. Mateos, "El conjunto provincial de culto imperial de Augusta Emerita", en Nogales y González (eds.), Culto... op. cit., 369-393.

98. Con respecto a la planta del templo, los argumentos sobre su carácter hexástilo y su desvinculación con el edificio tetrástilo del numerario de época tiberiana, consúltese: P. Mateos, "El templo...”, op. cit., 265269. Véase una opinión contraria en: Álvarez y Nogales, Forum Coloniae... op. cit., 297 y 298; y T. Nogales y J.M. Álvarez, "Fora Augustae Emeritae: la interpretatio provincial de los patrones metropolitanos", en D. Vaquerizo y J.F. Murillo (coord.), El concepto de lo provincial en el mundo antiguo. Homenaje a la profesora Pilar León, Córdoba, 2006, 439.

99. J.C. Saquete y J.M. Álvarez, "Culto imperial en Augusta Emerita: complejos monumentales y documentos epigráficos", en Nogales y González (eds.), Culto... op. cit., 406-407.

100. J.L. de la Barrera, La decoración arquitectónica de los foros de Augusta Emerita, Roma, 2000, 174. 
en torno al año 30 del siglo I; unos resultados que se han extrapolado a la edificación del espacio sacro y del conjunto al completo ${ }^{101}$.

El principal argumento que ha promovido la vinculación del templo con el culto imperial es su similitud con la aedes Concordiae de Roma, reconstruida por Tiberio y reinaugurada en el año $10 \mathrm{~d}$. C. ${ }^{102}$. Por otro lado, destaca la información que proporcionan una serie de epígrafes, como el que recoge el nombre de dicho emperador -Tibe(erio) Caesari / Divi Augusti f(ilio)_ ${ }^{103}$, el de la Concordia Augusti ${ }^{104}$, la dedicación a Domiciano ${ }^{105}$, la que realiza G. Sulpicius [Ruf?] us, praeses provinciae Lusitaniae, a un emperador de finales del siglo III o principios del siglo $I^{106}$, o el fragmento de inscripción que hace referencia a una dedicación de un objeto, quizás una estatua, de 50 libras de plata ${ }^{107}$.

Asimismo, se considera que el enorme esfuerzo que supuso amortizar cuatro manzanas de casas para construir el conjunto monumental sólo podía ser consecuencia de la organización de un culto que superara el nivel cívico en Lusitania. Se ha planteado incluso la hipótesis de que L. Fulcinius Trio, gobernador de provincia en época de Tiberio, tuviera un papel des-

101. Mateos, “El templo...,, op. cit. 270-271. La existencia de estructuras más antiguas al conjunto mostraron que no se trataba de un proyecto fundacional de la ciudad como se había planteado tradicionalmente: Mateos, “El conjunto...”, op. cit. 374.

102. En opinión de Mateos «se trata de una elección voluntaria de su planta, en un interés evidente por transferir a la capital lusitana el modelo arquitectónico del templo romano». «Esta traslación, por tanto, supone en sí mismo el deseo de vincular el edificio, así como su culto, con el emperador; no con Augusto sino con el propio Tiberio -por eso elige el edificio más representativo de su figura-. Tiberio, en el deseo de legitimar su sucesión, vincula el culto imperial al Divus Augustus, pero ejerciéndolo en el edificio más representativo de su política que lo relaciona con la familia Iulia». Véase sobre las citas: Mateos, "El templo..., loc. cit. 273-274.

103. J.L. Ramírez, Catálogo de las inscripciones imperiales de Augusta Emerita, Mérida, 2003, n 16; J. C. Saquete, "Materiales epigráficos procedentes del área del gran templo de culto imperial de Augusta Emerita. Una revisión necesaria”, Habis, 36, 2005, 278-281; y A.U. Stylow, "La epigrafía y el culto imperial en Augusta Emerita: nuevos epígrafes del conjunto provincial de culto imperial”, en Mateos (ed.), El "Foro... op. cit., 299-300.

104. Se han planteado varias fechas para el epígrafe que van desde el gobierno de Tiberio al siglo III: CIL II, 465; Ramírez, Catálogo... op. cit., no 52; Saquete, "Materiales..., op. cit., 281-283; y Stylow, "La epigrafía..., op. cit., 301-303.

105. CIL II, 477; Ramírez, Catálogo... op. cit., no 25; Saquete, “Materiales..., op. cit., 283-284; y Stylow, "La epigrafía...", op. cit., 303.

106. CIL II, 481; Ramírez, Catálogo... op. cit., no 60; Saquete, "Materiales..., op. cit., 287-288; y Stylow, "La epigrafía...", op. cit., 304. Además, Saquete no descarta que el epígrafe en el que se dedica un busto de oro a Tito (CIL II, 5264) y el homenaje del concilio provincial al senador L. Roscius Paculus -en ambas se menciona al concilium - provengan de este recinto: J. Saquete, "L. Fulcinius Trio, L. Cornelius Bocchus y el templo del Divus Augustus en Mérida”, Habis, 42, 2011, 168.

107. Una dedicación fechada en época julio-claudia en la que, según Stylow, aparece mencionado el gobernador de la provincia: Stylow, "La epigrafía...", op. cit., 308-311. Además, el autor establece una conexión entre la estructura del epígrafe y la inscripción que documenta la dedicación de un busto de oro a Tito, donde se menciona al gobernador y al flamen provinciae: CIL II, 5264. 
tacado en la edificación del templo ${ }^{108}$. Lo cierto es que para la configuración del complejo se eligió el punto topográficamente más elevado y céntrico de la ciudad que coincidía, incluso, con el trazado del cardo máximo, amortizado para la construcción de la plaza. Además, el espacio aumentó su cota de altura, constituyendo una plataforma sobreelevada con respecto a la urbe ${ }^{109}$.

La interpretación del recinto es una cuestión que no se ha zanjado pues para algunos historiadores los testimonios propuestos no son aún suficientes ${ }^{110}$. Ciertamente, no se conoce ninguna estructura en su entorno que se pueda vincular con las cuestiones administrativas, políticas o económicas en relación a la provincia ${ }^{111}$.

\section{Conclusiones}

El estudio del conjunto de manifestaciones que se incluyen bajo la denominación «culto imperial» sigue siendo un aspecto de la religión romana muy complejo. Como se ha querido mostrar en la introducción a estas páginas, desde su comienzo en Roma, la veneración a la domus imperatoria estaba interconectada con los rituales en honor al resto de deidades. Asimismo, el proceso de concentración de poder del princeps, a veces equiparable a los dioses para la población de su Imperio, favorecía el fenómeno de su divinización.

A pesar de la uniformidad u homogeneidad que se puede desprender de la denominación «culto imperial», se observa una variabilidad en cuanto a su desarrollo en Roma y en las provincias. Mientras que en la Vrbs el emperador se mostró como un primus inter pares, en Hispania se documentan dedicaciones y consagraciones con anterioridad a la divinización de Augusto en la capital. De este modo, a veces las manifestaciones provinciales se distanciaron del modelo augusteo.

108. J.C. Saquete, "L. Fulcinius Trio, Tiberio y el gran templo de culto imperial de Augusta Emerita", Epigraphica, 67, 2005, 279-308. A través de un nuevo epígrafe hallado en el foro de la colonia, Stylow y Ventura proponen que fuera $L$. Cornelius L. f. Bocchus, praefectus fabrum del gobernador $L$. Fulcinius Trio, el que dirigiera y organizara las obras del nuevo espacio público y del templo que lo presidía, dedicado en su opinión a Divus Augustus. La restitución del texto que realizan los autores es la siguiente: [L. Cornelio L. f. Bo]ccho / [pr. fabr. V L. Fulcini Tr]ionis cos. / [curatori templi Divi?] Augusti / [flamini provinc.] Lusitan. / [universi provinc.? co]nventus. Véase: A.U. Stylow y A. Ventura, "Los hallazgos epigráficos", Ayerbe, Barrientos y Palma (coord.), El foro... op. cit., 486-489. También en: P. Mateos et al., "Novedades arquitectónicas y epigráficas sobre el recinto de culto imperial provincial de la Lusitania", en Nogales y Rodà (eds.), Roma... op. cit., vol. II, 645-652. Consúltese la revisión que realiza Saquete sobre esta propuesta: Saquete, “L. Fulcinius Trio...”, op. cit. 163-172.

109. Mateos, “El templo..., op. cit., 271-276.

110. Consúltense por conveniencia: Trillmich, "Foro..., op. cit., 122; W. Trillmich, "Reflejos del programa estatuario del Forum Augustum en Mérida”, en J. Massó y P. Sada (eds.), Actas de la II Reunión sobre escultura romana en Hispania, Tarragona, 1996, 271 y s.; S. Panzram, Stadtbild und Elite: Tarraco, Corduba und Augusta Emerita zwischen Republik und Spätantike, Stuttgart, 2002, 253; y Saquete, "Materiales...", op. cit., 289-297.

111. Mateos, “El conjunto...”, op. cit., 336. 
La élite que ocupaba los cuadros de poder local en los centros hispanos se hizo con el control de los sacerdocios cívicos y promovió, a través de una actividad munificente, el avance de la nueva ideología imperial. Los rituales se incluyeron en la religión cívica por lo que su integración y desarrollo fue más rápido, y su implantación más profunda, en las regiones con amplia concentración de urbes. El culto imperial se convirtió, además, en un rasgo de «romanidad» que se inició precisamente en primer lugar en las zonas más próximas culturalmente a Roma.

Los últimos avances en el conocimiento de la veneración del emperador y su domus en la Península Ibérica han estado ligados, en gran medida, al desarrollo de las intervenciones arqueológicas. Como se ha mostrado en las últimas páginas, actualmente la investigación presta especial atención a determinar el comienzo de la organización supra-cívica del culto imperial en la Tarraconense, la Lusitania y la Bética, así como la localización de las sedes de culto en las capitales provinciales.

Por un lado, en Tarraco parece complicado casar el texto de Tácito sobre la solicitud a Tiberio para construir un templo a Divus Augustus en la colonia -y los numerarios tiberianos en los que quizás se muestre el edificio- con los testimonios epigráficos y arqueológicos de época flavia. Por el contrario, aunque en Emerita no se conoce ninguna noticia sobre el modo en el que se desarrolló la iniciativa a través de la cual comienza la organización de un culto imperial provincial en el territorio, sí se constatan flamines provinciae desde época julioclaudia -a diferencia de lo que ocurre en la Tarraconense y en la Bética. Más complicado es localizar la sede del culto ya que aunque buena parte de los estudiosos la sitúan en el complejo que se edificó en torno al templo de la calle Holguín, la aceptación no es unánime debido a la ausencia de pruebas definitivas que permitan atribuir un uso provincial al área, así como la inexistencia de testimonios que determinen la advocación del espacio sacro. En último lugar, el estado de la cuestión en la Bética es aún más complejo. La ausencia de epígrafes de flamines provinciae Baeticae en época julio-claudia y la negativa de Tiberio a la construcción de un templo dedicado a él mismo y a su madre han hecho retrasar la cronología al gobierno de los flavios; sin embargo, a través de la documentación arqueológica se constatan diferentes espacios con una datación anterior que se han puesto en relación con esta manifestación cultual.

Sin lugar a dudas la transformación y monumentalización que experimentaron los diferentes centros cívicos hispanos desde comienzos del Principado fue acompañada de la incorporación de una arquitectura que permitía que el emperador y los miembros de su domus estuvieran siempre presentes ante los ojos de sus súbditos ${ }^{112}$. La información arqueológica y epigráfica constata la posición privilegiada que toma la familia imperial en esta transformación urbana, pues sus imágenes fueron localizadas en numerosas áreas públicas y de representación. No obstante, la multiplicación de los espacios que acogieron a la domus Augusta no siempre se correspondió con lugares relacionados con su culto y liturgia. Ciertamente, sin inscripciones que determinen la funcionalidad de los recintos sólo debe haber hipótesis de trabajo.

112. Price, Rituals... op. cit., 135. 
